\title{
1 Reactive oxygen species prevent lysosome coalescence during 2 PIKfyve inhibition
}

4 Golam T. Saffi ${ }^{1,2,3}$, Evan Tang ${ }^{2}$, Subothan Inpanathan ${ }^{1,2}$, Sami Mammad ${ }^{1}$, Aaron Fountain ${ }^{1,2}$

5 Leonardo Salmena ${ }^{3,4}$, and Roberto J. Botelho ${ }^{1,2, *}$

$6{ }^{1}$ Molecular Science Graduate Program and ${ }^{2}$ Department of Chemistry and Biology, Ryerson

7 University, Toronto, Ontario, M5B 2K3 Canada

$8 \quad{ }^{3}$ Department of Pharmacology \& Toxicology, University of Toronto, Toronto, Ontario M5S

9 1A8, Canada

$10{ }^{4}$ Princess Margaret Cancer Centre, University Health Network, Toronto, Ontario M5G 1L7,

11 Canada

12

13 *To whom correspondence should be sent to: rbotelho@ ryerson.ca

14

15 Running title: Reactive oxygen species prevent lysosome enlargement

16

17 Keywords: Lysosomes, reactive oxygen species, membrane trafficking, organelles, fusion, 18 fission, cytoskeleton

19

20 Abbreviations: CDNB: 1-chloro-2,4,-dinitrobenzene; FBS: fetal bovine serum; HPF:

21 hydroxylphenyl fluorescein; LAMP1: lysosomal membrane protein-1; LLMeO: L-leucyl-L-

22 leucine methyl ester; MCB: monochlorobimane; MCOLN1: Mucolipin-1; NAC: N-acetyl-L- 
23 cysteine; PFA: paraformaldehyde; PtdInsP: phosphoinositide; PtdIns(3,5)P 2 : phosphatidylinositol-

24 3,5-bisphosphate; RILP: Rab-Interacting Lysosomal Protein; ROS: reactive oxygen species

26 Acknowledgement: ARPE-1 (RPE) cells stably expressing clathrin heavy chain-eGFP were a

27 kind gift from Dr. Costin Antonescu. We would also like to thank Mr. Janusan Baskararajah for

28 technical assistance.

29 Funding: This work was funded by grants awarded to RJB from the Natural Sciences and

30 Engineering Council of Canada (Grant numbers 372687-2010, 441595-2013, RGPIN-2020-

31 04343) the Canada Research Chairs Program, Canada Foundation for Innovation (32957) an Early

32 Researcher Award from the Government of Ontario (ER13-09-042), and contributions from

33 Ryerson University. The funders had no role in the study design, data collection and analysis,

34 decision to publish, or preparation of the manuscript.

\section{Abstract}

36 Lysosomes are terminal, degradative organelles of the endosomal pathway that undergo repeated

37 fusion-fission cycles with themselves, endosomes, phagosomes, and autophagosomes. Lysosome

38 number and size depends on balanced fusion and fission rates. Thus, conditions that favour fusion

39 over fission can reduce lysosome numbers while enlarging their size. Conversely, favouring fission

40 over fusion may cause lysosome fragmentation and increase their numbers. PIKfyve is a

41 phosphoinositide kinase that generates phosphatidylinositol-3,5-bisphosphate to modulate

42 lysosomal functions. PIKfyve inhibition causes an increase in lysosome size and reduction in

43 lysosome number, consistent with lysosome coalescence. This is thought to proceed through

44 reduced lysosome reformation and/or fission after fusion with endosomes or other lysosomes.

45 Previously, we observed that photo-damage during live-cell imaging prevented lysosome 
coalescence during PIKfyve inhibition. Thus, we postulated that lysosome fusion and/or fission dynamics are affected by reactive oxygen species (ROS). Here, we show that ROS generated by various independent mechanisms all impaired lysosome coalescence during PIKfyve inhibition

49 and accelerated lysosome fragmentation during re-activation. However, depending on the ROS

50 species or mode of production, lysosome dynamics were affected distinctly. $\mathrm{H}_{2} \mathrm{O}_{2}$ impaired

51 lysosome motility and reduced lysosome fusion with phagosomes, suggesting that $\mathrm{H}_{2} \mathrm{O}_{2}$ reduces

52 lysosome fusogenecity. In comparison, inhibitors of oxidative phosphorylation, glutathione, and

53 thioredoxin that produce superoxide, did not impair lysosome motility but instead promoted

54 clearance of actin puncta on lysosomes formed during PIKfyve inhibition. Additionally, actin

55 depolymerizing agents prevented lysosome coalescence during PIKfyve inhibition. Thus, we

56 discovered that ROS can generally prevent lysosome coalescence during PIKfyve inhibition using

57 distinct mechanisms depending on the type of ROS.

\section{Introduction}

60 Lysosomes are typically defined as terminal organelles with an acidic and degradative lumen that

61 digest macromolecules received through endocytosis, phagocytosis and autophagy [1-3]. In

62 reality, lysosomes are part of an endomembrane spectrum formed through heterotypic and

63 homotypic fusion between late endosomes that enclose cargo for degradation, terminal lysosomes,

64 which are non-acidic, hydrolase-dormant storage organelles, and endolysosomes, hybrids formed

65 when late endosomes and terminal lysosomes fuse together [4-7]; we use the term lysosome to

66 refer to this spectrum. Importantly, fusion and content exchange along the lysosomal spectrum

67 proceeds through two major routes. First, lysosomes can fuse with a target organelle resulting in

68 complete merger of the two compartments. Alternatively, lysosomes can exchange content with 
another target organelle through "kiss-and-run"; in this process, a transient fusion between two organelles generates an aqueous pore to exchange content and is followed by fission to prevent

71 amalgamation of the two compartments [6,8-10].

72 Delivery of cargo to lysosomes is an incessant process that depends on cargo sorting,

73 membrane targeting, and the fusion machinery, which are governed by, among others, the

74 lysosomal GTPases, Rab7 and Arl8b [11,12]. These GTPases modulate the movement of

75 lysosomes along microtubule tracks through their effectors; Rab7 uses Rab-Interacting Lysosomal

76 Protein (RILP) and FYVE and Coiled-Coil Domain Autophagy Adaptor-1 (FYCO1) to engage

77 dynein and kinesins, thus moving lysosomes towards the cell centre and periphery, respectively

78 [13,14]. In comparison, Arl8b uses Pleckstrin-Homology and RUN domain containing M2

79 (PLEKHM2; or SKIP) protein to engage kinesin to promote lysosome positioning to the cell

80 periphery [15]. When lysosomes contact other lysosomes/late endosomes, this engages tether

81 complexes like Homotypic Fusion Protein Sorting (HOPS) complex, also modulated by Rab7 and

82 Arl8b, and eventually undergo fusion [12,16,17]. Lysosome fusion and fission dynamics is also

83 modulated by intralysosomal $\mathrm{Ca}^{2+}$ release via Mucolipin-1 (MCOLN1) and P2X4 channels

$84[18,19]$.

85 Despite the incessant delivery of content to lysosomes through fusion, cells maintain

86 lysosome number and size, suggesting that exit of cargo from lysosomes by fission is also

87 relentless. Yet, much less is known about lysosome fission, which may proceed through

88 vesiculation, tubulation, and splitting [10]. Lysosome fission mechanisms may include classical

89 coat and fission machinery such as clathrin and dynamin and actin complexes [10,20-24].

90 Coordination of these fission machines is poorly understood but likely involves MCOLN1-Ca ${ }^{2+}$

91 release $[19,25,26]$. Additionally, phosphoinositides (PtdInsPs) play a key role in lysosome fission 
92 dynamics including modulation of vesiculation versus tubulation [10]. Amongst these, lysosome

93 fission-fusion cycles are coordinated by the Phosphoinositide Kinase, FYVE-type Zinc Finger

94 Containing (PIKfyve) lipid kinase that synthesizes phosphatidylinositol-3,5-bisphosphate

$95\left[\operatorname{PtdIns}(3,5) \mathrm{P}_{2}\right]$ and directly or indirectly, phosphatidylinositol-5-phosphate [27,28].

96 Pharmacological or genetic disruption of PIKfyve and partner proteins like Vac14 and the Fig4

97 phosphatase cause enlarged lysosomes, partly by impairing fission and reformation of terminal

98 lysosomes [4,27,29-31]. The result is lysosome coalescence, enlarging lysosomes while reducing

99 their numbers [4,30]. It remains unclear how PIKfyve controls lysosome fission but may involve

100 control of actin-assembly on lysosomes and fission proteins [19,21,26,32].

$101 \quad$ During our studies with acute PIKfyve inhibition, we observed that imaging by spinning

102 disc confocal microscopy at high frequency inhibited lysosome enlargement caused by PIKfyve

103 inhibition [30]. We speculated that this resulted from photo-generated reactive oxygen species

104 (ROS), which can include superoxide anions $\left(\mathrm{O}_{2}^{-}\right)$, hydrogen peroxide $\left(\mathrm{H}_{2} \mathrm{O}_{2}\right)$, and hydroxyl

105 radicals $(\mathrm{OH} \cdot)$ [33-35]. ROS species are also formed as part of normal aerobic metabolism and

106 can actually be produced as signaling intermediates to modulate cell proliferation and the

107 inflammatory response [36,37]. Yet, overt ROS production is detrimental, damaging proteins,

108 lipids, and DNA. Thus, cells have evolved multiple systems to quench ROS levels such as $\mathrm{O}_{2}^{-}$

109 dismutase, catalase, glutathione, and thioredoxin [37,38].

110 In this study, we sought to understand if other modes of ROS generation could abate

111 lysosome coalescence during PIKfyve inhibition and to better define the mechanisms of action.

112 Strikingly, we found that different sources of ROS reduced lysosome coalescence during PIKfyve

113 inhibition and accelerated lysosome fragmentation upon PIKfyve reactivation. Interestingly, these

114 distinct ROS hindered lysosome coalescence differently. $\mathrm{H}_{2} \mathrm{O}_{2}$ prevented lysosome coalescence 
115 by impairing lysosome motility and blunting lysosome fusogenecity. In comparison, oxidative

116 decoupling of the mitochondria with rotenone and inhibitors of glutathione and thioredoxin

117 counteracted lysosome coalescence by releasing actin clusters that accumulated on lysosomes

118 during PIKfyve impairment.

120 Results

121 Stimulation of ROS suppresses lysosome enlargement during acute 122 PIKfyve inhibition

123 We previously observed that extended laser excitation by spinning disc confocal fluorescence

124 microscopy arrested lysosome enlargement during acute PIKfyve suppression [30]. We speculated

125 that this arrest may be due to ROS production caused by light energy [39]. This led us to

126 hypothesize that other mechanisms of ROS generation could impair lysosome enlargement during

127 acute inhibition of PIKfyve. To test this, we exposed cells to a variety of ROS inducers: $\mathrm{H}_{2} \mathrm{O}_{2}$,

128 rotenone, which decouples the mitochondrial electron chain, monochlorobimane (MCB), a

129 glutathione S-transferase inhibitor, or to the thioredoxin inhibitor, 1-chloro-2,4,-dinitrobenzene

130 (CDNB) [35,40-42]. We first demonstrated that these manipulations enhanced ROS levels by

131 using CellROX Green, a redox sensitive dye whose fluorescence is proportional to ROS levels

132 (Figs 1A-B). Additionally, ROS cause MCB to form fluorescent MCB-glutathione adducts; we

133 observed 7x more MCB-glutathione adducts relative to vehicle (Fig 1C-1D). To better define the

134 type(s) of ROS generated by these treatments, we used fluorescent detectors for $\mathrm{O}_{2}^{-}$(ROS-ID),

135 mitochondrial $\mathrm{O}_{2}^{-}$(MitoSox), $\mathrm{OH} /$ peroxynitrite (HPF), and singlet $\mathrm{O}_{2} \cdot$ (si-DMA). We found that

$136 \mathrm{H}_{2} \mathrm{O}_{2}$ was the most promiscuous agent generating all species except detectable levels of singlet $\mathrm{O}_{2}$. 
137 (Fig 1E-H). In turn, rotenone generated mitochondrial $\mathrm{O}_{2}^{-}$and singlet $\mathrm{O}_{2} \cdot$ as detected by MitoSox

138 and si-DMA, respectively (Fig 1E-H), while CDNB favoured production of singlet $\mathrm{O}_{2}{ }^{*}$ (Fig $1 \mathrm{E}-$

$139 \mathrm{H})$. MCB did not elicit detectable changes in these probes, though ROS were detected when using

140 CellRox and GSH-MCB (Fig 1-D).

141 Remarkably, we then observed that all ROS inducers arrested lysosome enlargement in

142 cells treated with apilimod, a potent and selective PIKfyve blocker (Fig 2). More specifically,

143 RAW cells treated with apilimod alone suffered an increase in the size of individual lysosomes

144 (Fig 2B) and a decrease in lysosome number (Fig 2C), indicating that lysosomes coalesced. As we

145 documented before, the total cellular volume of the lysosome population was unchanged between

146 resting and apilimod-treated cells (Fig 2D). In comparison, co-exposure of cells with apilimod to

147 either $\mathrm{H}_{2} \mathrm{O}_{2}$, rotenone, $\mathrm{MCB}$ or $\mathrm{CDNB}$ prevented lysosome enlargement and reduction in lysosome

148 number (Fig 2A-D). Moreover, we used auranofin as a complementary thioredoxin inhibitor to

149 CDNB and observed that it too prevented apilimod-induced lysosome coalescence (Fig 2A-D). To

150 test whether lower $\mathrm{H}_{2} \mathrm{O}_{2}$ levels $(100 \mu \mathrm{M})$ could also block lysosome coalescence, we used lower

151 apilimod concentrations (1 or $5 \mathrm{nM})$. We still observed lysosome coalescence at these lower

152 concentrations of apilimod and this was prevented in cells that were co-exposed to $100 \mu \mathrm{M} \mathrm{H}_{2} \mathrm{O}_{2}$

153 (S1 Fig). No significant changes to lysosome number, size of individual lysosomes and total

154 lysosome volume were observed when ROS agonists were used alone (Fig 2A-D). The fact that

155 ROS alone did not appear to further reduce lysosome size and increase lysosome number may

156 reflect some physical restriction to the smallest lysosome size; for example, osmotic pressure may

157 prevent a further reduction in the size of basal lysosomes.

158 To provide evidence that ROS were the active agents that blocked lysosome coalescence

159 during apilimod-treatment, we employed N-acetyl-L-cysteine (NAC) as an anti-oxidant during 
rotenone co-administration [43]. Indeed, cells co-exposed with apilimod, rotenone and NAC

161 displayed larger lysosomes than cells co-treated with apilimod and rotenone (Fig 3), indicating

162 that ROS are the active agents arresting lysosome enlargement during PtdIns $(3,5) \mathrm{P}_{2}$ depletion.

163 To ensure that these observations were not specific to murine RAW macrophages, we

164 assessed apilimod-induced lysosome coalescence in human-derived RPE and HeLa cells co-

165 exposed to $\mathrm{H}_{2} \mathrm{O}_{2}$ or CDNB. As with RAW cells, while apilimod-alone induced lysosome

166 coalescence in HeLa and RPE cells, counterpart cells co-administered apilimod and $\mathrm{H}_{2} \mathrm{O}_{2}$ or

167 CDNB resisted lysosome enlargement and reduction in lysosome number (S2 Fig). As before, no

168 changes were observed under any treatment to the total lysosomal volume within these cell types

169 (S2D, S2H Figs). Overall, our observations suggest that generation of ROS via distinct

170 mechanisms can impair lysosome coalescence caused by PIKfyve inhibition in several cell types.

171 ROS accelerate lysosome fragmentation during PIKfyve reactivation

172 Removal of apilimod elicited reversal of lysosome coalescence, re-establishing lysosome size and

173 number after $>3 \mathrm{~h}$ post drug removal [30]. To test if ROS exposure could accelerate this reversal

174 in lysosome coalescence, we treated RAW cells with apilimod for $1 \mathrm{~h}$ and then incubated cells

175 with fresh, drug-free medium to reactivate PIKfyve with or without $\mathrm{H}_{2} \mathrm{O}_{2}$, rotenone, CDNB, or

176 MCB during this wash duration. As before, apilimod increased lysosome size and decreased

177 lysosome number, while chasing cells for $2 \mathrm{~h}$ after drug removal reversed this phenotype partly;

178 longer incubation ultimately reverses lysosome enlargement completely [30]. Exposure to any of

179 the ROS agents during the apilimod-free chase accelerated the rate of lysosome fragmentation,

180 rapidly increasing lysosome number and reducing the size of individual lysosomes (Fig 4A-D).

181 Overall, ROS prevented and reversed lysosome coalescence induced by PIKfyve

182 inhibition. We next examined levels of PtdIns(3,5) $\mathrm{P}_{2}$, lysosome membrane damage, lysosome 
185 ROS stimulation arrests apilimod induced lysosome enlargement 186 without neutralizing apilimod or stimulating $\operatorname{PtdIns}(\mathbf{3}, 5) \mathbf{P}_{2}$ synthesis

187 To understand the effect of ROS on apilimod-mediated lysosome enlargement, we first considered apilimod, relieving the acute PIKfyve suppression, and thus preventing lysosome coalescence. To test this, we co-incubated apilimod with $\mathrm{H}_{2} \mathrm{O}_{2}$ in complete medium in vitro for 40 min. Following

191 this incubation, we added catalase to decompose $\mathrm{H}_{2} \mathrm{O}_{2}$ and then transferred the reaction mixture 192 onto RAW macrophages to observe if apilimod was still able to induce lysosome enlargement. We

193 found that apilimod pre-exposed to $\mathrm{H}_{2} \mathrm{O}_{2}$ was still able to increase lysosome size and decrease

194 lysosome number similarly to an aliquot of naïve apilimod (Fig 5A-D), suggesting that $\mathrm{H}_{2} \mathrm{O}_{2}$ did 195 not degrade apilimod. Moreover, while $\mathrm{H}_{2} \mathrm{O}_{2}$ arrested apilimod-mediated lysosome enlargement, 196 the co-addition of catalase to apilimod and $\mathrm{H}_{2} \mathrm{O}_{2}$ permitted lysosome enlargement, further 197 suggesting that $\mathrm{H}_{2} \mathrm{O}_{2}$ is a direct suppressor of lysosome coalescence in PIKfyve-inhibited cells 198 (Fig 5A-D). Therefore, we provide additional evidence that ROS rescue lysosome coalescence 199 during acute PIKfyve inhibition.

We next examined if ROS rescue lysosome coalescence during PIKfyve inhibition by

201 increasing the levels of PtdIns(3,5) $\mathrm{P}_{2}$ in cells. In part, this may occur because ROS species 202 reversibly oxidize catalytic cysteine residues on protein and lipid phosphatases, abating their 203 activity $[37,44,45]$. Therefore, augmented ROS levels may inhibit the Fig4 lipid phosphatase, 204 counteracting PIKfyve inhibition with apilimod and boosting PtdIns(3,5) $\mathrm{P}_{2}$ levels [31]. This 205 putative PtdIns(3,5) $\mathrm{P}_{2}$ elevation may then be sufficient to prevent lysosome coalescence in cells 
exposed to apilimod and ROS. To test this hypothesis, we measured PtdInsP levels in cells treated with $\mathrm{H}_{2} \mathrm{O}_{2}$ or rotenone with and without apilimod by labelling cells with ${ }^{3} \mathrm{H}-m y o$-inositol and using HPLC-coupled flow scintillation [46]. However, we observed a similar drop of about $80 \%$ in

209 Ptdns $(3,5) \mathrm{P}_{2}$ in cells treated with apilimod with or without ROS agents (Fig 5E, F), suggesting that

210 ROS stimulation does not significantly elevate PtdIns(3,5) $\mathrm{P}_{2}$ levels. In addition, inhibition of

211 PIKfyve typically causes an increase in PtdIns(3)P levels (Fig 5E, F). While rotenone had no effect

212 on this increase, $\mathrm{H}_{2} \mathrm{O}_{2}$ appeared to prevent this spike in PtdIns(3)P levels during apilimod treatment

213 (Fig 5E). The significance of this change is not clear to us but given that rotenone still increased

214 PtdIns(3)P and prevented lysosome coalescence, it is not likely to explain our observations.

215 Overall, ROS prevents lysosome coalescence during PIKfyve inhibition via a mechanism that is 216 independent of PtdIns(3,5) $\mathrm{P}_{2}$ levels.

\section{ROS alter the microtubule system}

218 Since PtdIns $(3,5) \mathrm{P}_{2}$ levels do not illuminate how ROS prevent lysosome coalescence during

219 PIKfyve inhibition, we assessed other processes that affect lysosome dynamics. First, we examined

220 whether ROS altered the microtubule system given its role in facilitating homotypic and

221 heterotypic lysosome fusion. In fact, we previously showed that disruption of the microtubule

222 system and microtubule motor activity blocked lysosome coalescence during PIKfyve inhibition

223 [30]. We inspected the microtubule system in RAW macrophages (Fig 6A-D) and RPE cells (Fig

$2246 \mathrm{E}-\mathrm{H})$ exposed to the ROS agents by immunofluorescence staining against $\alpha$-tubulin. We observed

225 that the ROS agonists altered the microtubule system, but in distinct ways. Relative to untreated

226 RAW macrophages or RPE cells, qualitative analysis of immunofluorescence images suggest that

$227 \mathrm{H}_{2} \mathrm{O}_{2}$ makes microtubules more stable and extended, whereas increasing concentrations of 228 rotenone, $\mathrm{CDNB}$ and $\mathrm{MCB}$ seemed to depolymerize microtubules, resulting in shorter 
microtubules and diffused staining (Fig. 6). As a proxy to quantify changes to the microtubule morphology, we employed and validated the use of ImageJ "skeleton" plugin to extract different

231 parameters of microtubule structure; these included filament junctions, branching, branch length, 232 and patch area (S3 Fig). It is important to state that these are proxies rather than absolute 233 descriptors of microtubule morphology. Using these measures, we were able to quantitatively

234 show that all four ROS types altered the microtubule system with distinct effects. Briefly, $\mathrm{H}_{2} \mathrm{O}_{2}$ 235 increased the number of microtubule junctions per cell and branch length in both RAW and RPE 236 cells (Fig 6B, D, F and H). In comparison, rotenone, CDNB and MCB decreased the number of 237 microtubule junctions and branches per cell significantly in RAW cells and increased the patch 238 area in RPE cells (Fig. 6B, C, I). These observations indicate that type of ROS and/or the site of 239 ROS synthesis differentially affects microtubules, and potentially lysosome dynamics.

\section{Disparate ROS effects on lysosome motility}

241 To dissect these observations further, we considered that microtubule disruption would impair

242 lysosome motility and/or lysosome fusion. To test this model, we quantified lysosome motility and

243 the ability of lysosomes to fuse with phagosomes. First, we conducted live-cell imaging over 3

244 and 6 min for RAW macrophages (Fig. 7A-C, Movies 1-6) and RPE cells (Fig. 7D-F, Movies $7-$

245 13), respectively, treated with vehicle or ROS agents. Using these videos, we then extracted

246 lysosome speed, track length, and vectorial displacement as indicators of lysosome motility. To

247 our surprise, $\mathrm{H}_{2} \mathrm{O}_{2}$ was the only ROS agent that reduced lysosome speed, track length and vectorial

248 displacement in RAW and in RPE cells, with the strongest effect on the latter cell type (Fig. 7). To

249 understand whether microtubule stability was sufficient to impair lysosome coalescence or affect

250 lysosome motility, we performed a control experiment by treating RAW cells with paclitaxel, a 251 microtubule stabilizing agent [47]. However, paclitaxel did not impair lysosome coalescence 
caused by apilimod and may actually enhance lysosome motility indicators (S4 Fig, Movies 14-

253 16), suggesting that $\mathrm{H}_{2} \mathrm{O}_{2}$ blocks apilimod-mediated lysosome enlargement via a distinct

254 mechanism, perhaps by displacing motors from lysosomes or impairing motor activity. If so, this

255 does not seem to occur by reducing the levels of GTP-Rab7 or Arl8b GTPase loaded onto

256 lysosomes as measured by imaging and membrane fractionation (S5 Fig).

257 Given the impaired lysosome motility caused by $\mathrm{H}_{2} \mathrm{O}_{2}$, we next sought to determine if $\mathrm{H}_{2} \mathrm{O}_{2}$

258 also hindered lysosome fusogenecity by examining phagosome-lysosome fusion as a model. RAW

259 cells were treated with $\mathrm{H}_{2} \mathrm{O}_{2}$ or vehicle for $1 \mathrm{~h}$, followed by phagocytosis of bacteria for 20 min

260 and a chase period of 40 min to permit phagosome maturation. The degree of phagosome-lysosome

261 fusion was assessed by quantifying the amount of LAMP-1 fluorescent signal present on bacteria-

262 containing phagosomes. We observed that $\mathrm{H}_{2} \mathrm{O}_{2}$-treated RAW cells had less LAMP-1 fluorescence

263 signal localized to bacteria-containing phagosomes compared to vehicle-treated RAW

264 macrophages (Fig 8). This suggests that $\mathrm{H}_{2} \mathrm{O}_{2}$ impaired the ability of lysosomes to fuse with target

265 organelles, consistent with reduced lysosome motility. Overall, we propose that $\mathrm{H}_{2} \mathrm{O}_{2}$ prevents

266 lysosome coalescence during PIKfyve inhibition by impairing lysosome motility and the

267 probability of fusion with other organelles, including phagosomes or other lysosomes.

In comparison to $\mathrm{H}_{2} \mathrm{O}_{2}$, rotenone, $\mathrm{MCB}$ and $\mathrm{CDNB}$ did not impair measures of lysosome

269 motility in RAW macrophages or RPE cells (Fig 7A-C) at concentrations sufficient to block

270 apilimod-induced lysosome coalescence. Interestingly, nocadozole strongly impaired all measures

271 in RPE cells but had mild effects on RAW cells (Fig 7). This is likely because RAW macrophages

272 depolymerized for microtubules appeared to become rounder and taller, causing a wobbling

273 motion that moved lysosomes in bulk (see Supplemental Movies 1-6). In comparison, RPE cells

274 were flatter and more resistant to this oscillating effect (see Supplemental Movies 7-13). Given 
275 that nocodazole in RPE cells hindered lysosome motility, but CDNB, MCB and rotenone had no

276 effect on lysosome motility measures in RPE cells, this suggests that rotenone, CDNB and MCB

277 only partially disrupt the microtubule system. Thus, the extent of microtubule depolymerization

278 caused by rotenone, $\mathrm{CDNB}$ and $\mathrm{MCB}$ is not sufficient to explain how these agents prevent

279 lysosome enlargement during apilimod treatment.

280 ROS effects on lysosome membrane damage and $\mathrm{Ca}^{2+}$ release

281 Given the above, we next assessed if and how ROS affected other lysosome properties. One

282 possibility is that ROS damage the membrane of lysosomes altering their dynamics. To test this,

283 we transfected RAW macrophages with galectin-3-GFP, which labels damaged lysosomes with

284 exposed luminal glycoproteins to the cytosol [48,49]. Strikingly, under the conditions used, $\mathrm{H}_{2} \mathrm{O}_{2}$

285 or rotenone did not induce a significantly higher number of galectin-3-GFP punctate relative to

286 vehicle-treated cells. As a positive control, we observed a much higher number of galectin-3-GFP

287 puncta in cells exposed to the lysosome damaging agent, LLMeO (Fig 9). Thus, we suspect that

288 membrane damage cannot account for the broad ROS-mediated prevention of lysosome

289 enlargement during PIKfyve inhibition.

290 We next considered if ROS could trigger release of lysosomal $\mathrm{Ca}^{2+}$, which in turn could

291 alter lysosome dynamics [25,50]. In fact, ROS have been connected to release of lysosomal $\mathrm{Ca}^{2+}$

292 via MCOLN1 [51]. To examine if lysosomal $\mathrm{Ca}^{2+}$ is released by ROS agents, we quantified the

293 lysosome-to-cytosol fluorescence ratio of Fluo4-AM, a $\mathrm{Ca}^{2+}$ sensor [52,53], in rotenone and $\mathrm{H}_{2} \mathrm{O}_{2-}$

294 treated cells. Whereas rotenone had no apparent effect in this ratio, we observed an increase in

295 cytosolic $\mathrm{Ca}^{2+}$ levels relative to lysosome in $\mathrm{H}_{2} \mathrm{O}_{2}$-treated cells (Fig. 10A, B). However, pre-

296 treating cells with BAPTA-AM did not affect basal lysosome number and volume, or block

297 apilimod-induced lysosome coalescence, nor did it alter $\mathrm{H}_{2} \mathrm{O}_{2}$ or rotenone prevention of lysosome 
coalescence (Fig. 10C-F). Overall, the data suggest that the effects by ROS are not likely mediated

by $\mathrm{Ca}^{2+}$ or lysosome damage.

300 Clathrin and dynamin are not required for ROS-induced lysosome 301 fragmentation

302 Lysosomes and related organelles such as autolysosomes can assemble fission machinery,

303 including the canonical fission components, clathrin and dynamin $[10,23,24,54]$. We sought to

304 determine if ROS species like $\mathrm{H}_{2} \mathrm{O}_{2}$ stimulate clathrin and dynamin-2 to boost fission and prevent

305 lysosome coalescence during PIKfyve inhibition. First, we observed no changes in the levels of

306 lysosome-associated clathrin-eGFP in vehicle or apilimod-treated RPE cells. In comparison,

307 clathrin-eGFP was recruited at higher levels to lysosomes labelled with Alexa ${ }^{546}$-conjugated

308 dextran after $\mathrm{H}_{2} \mathrm{O}_{2}$ treatment in both the presence or absence of apilimod (S6A-B Fig). To

309 complement our observations, we treated RAW 264.7 cells with vehicle or $\mathrm{H}_{2} \mathrm{O}_{2}$, followed by

310 sucrose gradient ultracentrifugation to fractionate organelles and probed for clathrin and dynamin

311 by Western blotting. We saw a consistent increase in the level of clathrin and dynamin-2 to

312 LAMP1-positive lysosome fractions in cells treated with $\mathrm{H}_{2} \mathrm{O}_{2}$ relative to resting cells (S6C-E

313 Fig). To test whether this enhanced recruitment of clathrin and dynamin aided in lysosome

314 fragmentation during PIKfyve reactivation in the presence of $\mathrm{H}_{2} \mathrm{O}_{2}$, we inhibited clathrin and

315 dynamin with ikarugamycin and dyngo-4a, respectively [55,56]. Nevertheless, there was no

316 significant difference in the $\mathrm{H}_{2} \mathrm{O}_{2}$-mediated rescue of lysosome coalescence during PIKfyve

317 reactivation when clathrin or dynamin were arrested (Fig 11, S7 Fig). Similarly, there was no

318 difference in lysosome fragmentation during rotenone exposure when cells were incubated with

319 dyngo-4a (S7 Fig). Overall, while at least $\mathrm{H}_{2} \mathrm{O}_{2}$ seems to recruit clathrin and dynamin to lysosomes 
320 (and perhaps other membranes), our data do not support a role for clathrin and dynamin in

321 preventing lysosome coalescence during PIKfyve inhibition under the used conditions.

\section{ROS prevents lysosome coalescence by actin depolymerization}

323 There is growing evidence that F-actin-based structures may regulate endosomal and lysosomal

324 fission, either through the action of acto-myosin constriction or the assembly of fission machinery

325 that remains to be fully defined $[10,21,57]$. In fact, work by Hong et al. suggests that PIKfyve

326 inhibition causes branched actin accumulation on endosomes; based on their markers used to

327 identify endosomes, lysosomes were likely included in their analysis [21]. We set to understand

328 if at least some ROS can prevent lysosome coalescence during PIKfyve inhibition by eliminating

329 these F-actin assemblies on lysosomes. Indeed, PtdIns $(3,5) \mathrm{P}_{2}$ depletion increased the number of

330 F-actin puncta associated with lysosomes detectable by fluorescent-phalloidin staining (Fig 12A,

331 B), as previously reported [58,59]. Interestingly, co-administration of rotenone or CDNB with

332 apilimod reduced F-actin puncta associated with lysosomes (Fig 12A, B). These observations

333 indicate that ROS generated by rotenone and CDNB help prevent or reverse lysosome coalescence

334 during PIKfyve inhibition by boosting actin turnover on lysosomes.

335 To further test whether actin depolymerization helps prevent lysosome coalescence during

336 PIKfyve inhibition and accelerate lysosome fragmentation during PIKfyve inhibition, we

337 compared lysosome volumetrics in cells treated with the actin depolymerizing agents, cytochalasin

338 B or latrunculin A. We found that both cytochalasin B and latrunculin A treatments hindered

339 lysosome coalescence during apilimod treatment, as well as accelerated lysosome fragmentation

340 after apilimod removal and PIKfyve reactivation (Fig 12C-F). Collectively, our observations

341 suggest that at least certain types of ROS prevent lysosome coalescence during acute PIKfyve

342 inhibition by alleviating F-actin amassed on lysosomes, likely facilitating fission. 


\section{Discussion}

345 Low PtdIns(3,5) $\mathrm{P}_{2}$ levels causes multiple defects including impaired autophagic flux, nutrient

346 recycling, and phagosome resolution [10,27]. These defects are likely derived from the inability

347 of lysosomes to reform or separate after fusion with other lysosomes, late endosomes, phagosomes,

348 and autolysosomes [4,10,30,60,61]. As a corollary, lysosomes coalesce to become larger but fewer

$349[4,30]$. Thus, identification of mechanisms or compounds that can drive lysosome fission may

350 prove useful to rescue autophagic flux, degradative capacity, and lysosome dynamics in cells

351 exhibiting reduced PtdIns(3,5) $\mathrm{P}_{2}$ levels. Such mechanisms or compounds may act to up-regulate

352 PtdIns $(3,5) \mathrm{P}_{2}$ levels in conditions of insufficient PIKfyve activity like those caused by null-

353 mutations in the Fig4 lipid phosphatase [29]. For example, the cyclin/cyclin-dependent kinase,

354 Pho80/Pho85, phosphorylates Fab1 to upregulate the levels of $\operatorname{PtdIns}(3,5) \mathrm{P}_{2}$ in response to

355 hypertonic shock, protecting yeast cells from osmotic shock [62,63]. Alternatively, activating

356 mechanisms downstream of PtdIns $(3,5) \mathrm{P}_{2}$ that enable lysosome fission directly may also rescue

357 lysosome dynamics.

We previously observed that photo-toxicity during live-cell imaging with spinning disc

359 confocal microscopy prevented lysosome coalescence during apilimod-mediated PIKfyve

360 inhibition [30]. While unfortunately blunting our ability to perform high spatio-temporal resolution

361 of lysosome enlargement by live-cell imaging, we questioned if other sources of ROS could also

362 prevent lysosome coalescence during PIKfyve inhibition. Indeed, we provide evidence here that

363 ROS generated by diverse approaches can counteract and even reverse lysosome coalescence

364 during PIKfyve inhibition. Notably, neither $\mathrm{H}_{2} \mathrm{O}_{2}$ or rotenone rescued lysosome size by up-

365 regulating the levels of PtdIns $(3,5) \mathrm{P}_{2}$. This suggests that ROS counteract lysosome coalescence by 
acting downstream of PtdIns $(3,5) \mathrm{P}_{2}$, or by stimulating parallel processes that promote lysosome

367 fission or impair lysosome fusion. Notably, ROS agents alone did not appreciably alter basal

368 lysosome properties like lysosome size and number. This may partially relate to resolution limit

369 of light microscopy as we estimate the radius of intact lysosomes to be $0.7 \mu \mathrm{m}$, or due to physical

370 constraints of lysosomes that prevent smaller average lysosome size, or perhaps because the

371 mechanisms responsible for basal lysosome dynamics are insensitive to ROS effects. Collectively,

372 our work suggests that ROS prevent lysosome enlargement during PIKfyve inhibition, but exact

373 mode of action may depend on ROS type, and/or mode of production, and/or location $\operatorname{since~} \mathrm{H}_{2} \mathrm{O}_{2}$

374 had distinct effects from those by CDNB/auranofin, MCB and rotenone.

375 We previously showed that disrupting the microtubule system with nocodazole or 376 impairing motor proteins abated lysosome coalescence during PIKfyve inhibition [30]. Thus, we 377 explored whether ROS agents disrupted lysosome motility, which would impair fusogenicity. We 378 observed that only $\mathrm{H}_{2} \mathrm{O}_{2}$ significantly arrested lysosome motility and reduced fusogenicity. In 379 addition, we also saw a more defined microtubule network in $\mathrm{H}_{2} \mathrm{O}_{2}$-treated cells, suggesting that 380 microtubules were stabilized by $\mathrm{H}_{2} \mathrm{O}_{2}$. Whether this effect is generalizable is debatable since there 381 are contradictory observations about the effect of $\mathrm{H}_{2} \mathrm{O}_{2}$ on the microtubule system, which may 382 depend on cell type and experimental conditions employed [64-66]. Regardless, microtubule 383 stabilization is not sufficient to impair lysosome motility since paclitaxel did not prevent lysosome 384 enlargement caused by apilimod or impair lysosome motility. Thus, we propose that $\mathrm{H}_{2} \mathrm{O}_{2}$ impairs 385 lysosome motility by disrupting motor activity, and/or impairing motor interactions with 386 lysosomes and/or microtubules. Mitochondria may offer some insight since their motility was also 387 arrested by $\mathrm{H}_{2} \mathrm{O}_{2}$ [65]. $\mathrm{H}_{2} \mathrm{O}_{2}$ stimulated $\mathrm{p} 38 \alpha$ MAPK, which then interrupted motor adaptor 388 complex function. Motors themselves retained their activity since forced anchorage of kinesin to 
mitochondria maintained mitochondrial motility in the presence of $\mathrm{H}_{2} \mathrm{O}_{2}$ [65]. Thus, $\mathrm{H}_{2} \mathrm{O}_{2}$ may

390 disrupt kinesin and/or dynein adaptors like RILP-ORP1L-dynein or SKIP-kinesin, though our

391 work suggests that this is not likely occurring by altering GTP-Rab7 and Arl8b loading onto

392 lysosomes.

394 by disrupting catalase and thioredoxin (MCB and CDNB/auranofin) partially depolymerized the

395 microtubule system under the employed conditions, though not sufficiently enough to hinder

396 lysosome motility. Instead, these agents may prevent overt lysosome coalescence by releasing a

397 dense F-actin network that assembles on lysosomes during PIKfyve inhibition. Consistent with

398 this, actin depolymerizers also reduced lysosome coalescence during acute PIKfyve inhibition and

399 accelerated lysosome fragmentation during PIKfyve reactivation. These observations may be

400 consistent with those by Hong et al., wherein PtdIns $(3,5) \mathrm{P}_{2}$ modulates branched actin dynamics

401 on endosomes (markers apply to lysosomes as well) by regulating cortactin [21]. The authors

402 showed that PIKfyve inhibition increased actin density on endo/lysosomes, which consequently

403 impaired fission and caused enlargement [21]. Additionally, PIKfyve was recently shown to

404 modulate branched F-actin to help drive melanosome maturation [58]. Indeed, branched F-actin

405 has emerged as a major player in membrane fission for endo/lysosomes nucleated by ER-

406 endo/lysosomes contact sites [67,68]. Thus, we propose that ROS generated by rotenone,

407 CDNB/auranofin, and perhaps MCB, may abate lysosome coalescence by relieving dense F-actin

408 networks that form on lysosomes during PIKfyve inhibition.

409 While oxidative stress in cells can hinder lysosome coalescence during PIKfyve inhibition

410 and accelerate lysosome fragmentation during PIKfyve reactivation, the exact mechanisms of

411 action depends on the type of ROS and/or mode of production. Of the treatments we employed, 
$412 \mathrm{H}_{2} \mathrm{O}_{2}$ was able to produce cytosolic and mitochondrial superoxide $\mathrm{O}_{2}^{-}$and $\mathrm{OH} \cdot$ radicals, but no 413 detectable levels of singlet $\mathrm{O}_{2}$ (Fig 1); likely, the ROS generated was delocalized as well. In

414 comparison, rotenone and $\mathrm{CDNB}$ released singlet $\mathrm{O}_{2}$, while rotenone also released mitochondrial

415 superoxide and singlet $\mathrm{O}_{2}^{-}$; neither treatment appeared to produce $\mathrm{OH}^{\cdot}$ radicals (Fig. 1). We

416 propose that the likely delocalized release of ROS and $\mathrm{OH} \cdot$ generated by $\mathrm{H}_{2} \mathrm{O}_{2}$ may stabilize

417 microtubules and impair motor dynamics, which then impinges on lysosome dynamics [69-71].

418 In comparison, mitochondrial $\mathrm{O}_{2}^{-}$and singlet $\mathrm{O}_{2}$ increases turnover of the lysosomal $\mathrm{F}$-actin

419 network to shift lysosome dynamics towards fission. While we could not detect specific ROS in

420 MCB, MCB interacts with GSH and with thiol residues of other enzymes such as thioredoxin

421 reductase, leading to increased $\mathrm{O}_{2}^{-}$production $[41,70,72]$. Overall, future work should aim to better

422 delineate the type of ROS and their exact target that alter lysosome dynamics. Moreover, since

423 ROS can serve as physiological signals [37,73], it is tempting to suggest that particular ROS may

424 play a role in coordinating localized processes like membrane fusion, motor activity, and 425 membrane fission. This process or the sensors engaged by ROS may represent approaches to 426 rescue lysosome dynamics in conditions of PtdIns $(3,5) \mathrm{P}_{2}$ insufficiency.

\section{Materials and Methods}

\section{Cell culture, plasmids, and transfection}

430 RAW 264.7 macrophages and HeLa cells were grown in Dulbecco's Modified Eagle Medium

431 (DMEM; Wisent, St Bruno, QC) supplemented with 5\% heat-inactivated fetal bovine serum (FBS;

432 Wisent). ARPE-1 (RPE) cells stably expressing clathrin light chain-eGFP were grown in

433 DMEM/F12 medium (Gibco) supplemented with 10\% FBS [74]. All cells were grown at 5\% $\mathrm{CO}_{2}$ 
434 and $37^{\circ} \mathrm{C}$ and routinely checked for contamination. FuGene HD (Promega, Madison, WI) was

435 used for transient transfections following manufacturer's instructions with a ratio of 3:1 FuGene

436 HD transfection reagent $(\mu \mathrm{l})$ to DNA $(\mu \mathrm{g})$. The transfection mixture was replaced with fresh

437 complete medium $4-5 \mathrm{~h}$ post-transfection and cells were used $24 \mathrm{~h}$ following transfection. RAW

438 cells were transfected with plasmids expressing Rab7-RILPC33-GFP (RILPC33-GFP), or wild-

439 type Arl8b-GFP (Arl8bWT-GFP), previously described in [13,75], or Galectin-3-GFP (Addgene;

440 [48]). The bacterial expression vector pZsGreen (Takara Bio USA, Inc., formerly Clontech

441 Laboratories, Inc., 632446) was transformed into E. coli DH5a to generate ZsGreen-expressing

442 bacteria.

443

\section{Pharmacological treatment of cells}

445 Apilimod (Toronto Research Chemicals, Toronto, ON) was used at $20 \mathrm{nM}$ for 40 min, unless

446 otherwise indicated, to deplete cellular PtdIns(3,5) $\mathrm{P}_{2} . \mathrm{H}_{2} \mathrm{O}_{2}$ (Bio Basic, Markham, ON) was used

447 as indicated. Rotenone, 1-chloro-2,4,-dinitrobenzene (CDNB), auranofin, and

448 monocholorobimane (MCB; Sigma-Aldrich, all from Sigma-Aldrich, Oakville, ON) were used as

449 indicated to generate ROS by respectively inhibiting mitochondrial respiratory chain complex,

450 glutathione, or thioredoxin reductase (CDNB and auranofin). Bovine liver catalase (Sigma-

451 Aldrich) and N-acetyl-L-cysteine (NAC) (Bio Basic) were used as anti-oxidants. Paclitaxel and

452 nocadozole (both from Sigma-Aldrich) were used at 1 or $10 \mu \mathrm{M}$ and 5 or $10 \mu \mathrm{M}$ to stabilize and

453 depolymerize microtubules, respectively. Latrunculin A (Abcam, Toronto, ON) and cytochalasin

$454 \mathrm{D}$ (EMD Millipore, Toronto, $\mathrm{ON}$ ) were used at $1 \mu \mathrm{M}$ and $5 \mu \mathrm{M}$, respectively to depolymerize

455 actin. Ikarugamycin (Sigma-Aldrich) and dyngo-4A (Abcam, Cambridge, MA) used to inhibit

456 clathrin and dynamin respectively. BAPTA-AM (Sigma-Aldrich) was used to chelate intracellular 
calcium and Fluo4-AM (ThermoFisher, Burlington, $\mathrm{ON}$ ) was used as a fluorescent $\mathrm{Ca}^{2+}$ probe. As

458 a positive control for lysosome damage, we treated cells for $2 \mathrm{~h}$ with $0.5 \mathrm{mM}$ L-leucyl-L-leucine

459 methyl ester (LLOMe; L7393, Sigma-Aldrich).

460

461 Lysosome labelling

462 Lysosomes were labelled by incubating cells with $200 \mu \mathrm{g} / \mathrm{mL}$ Alexa ${ }^{546}$-conjugated dextran or with

$463200 \mu \mathrm{g} / \mathrm{mL}$ Alexa $^{488}$-conjugated dextran (Thermo Fisher Scientific, Mississauga, ON) or with 2.5

$464 \mathrm{mg} / \mathrm{mL}$ Lucifer yellow (Thermo Fisher Scientific, Mississauga, ON) for $2 \mathrm{~h}$ in complete media at $46537{ }^{\circ} \mathrm{C}$ in $5 \% \mathrm{CO}_{2}$. Cells washed with phosphate-buffered saline (PBS) and resupplied with

466 complete cell-specific media for $1 \mathrm{~h}$ to chase the fluid-phase marker to lysosomes before 467 pharmacological manipulation and live-cell imaging. We note that we use "lysosomes" to 468 represent a potential mixture of late endosomes, lysosomes and endolysosomes (Bright et al., 1997;

469 Choy et al., 2018). Lysosomal calcium was labelled with Fluo-4AM $8 \mu$ M by pulsing for 45 min 470 in complete media at $37^{\circ} \mathrm{C}$ in $5 \% \mathrm{CO}_{2}$, followed by washing with PBS and addition of complete 471 media for 45 min to chase the marker to lysosomes.

\section{Live- and fixed-cell spinning disc confocal microscopy}

474 Microscopy and imaging were done with a Quorum DisKovery spinning disc confocal microscope

475 system equipped with a Leica DMi8 microscope connected to an iXON 897 EMCCD camera,

476 controlled by Quorum Wave FX powered by MetaMorph software, using 63x 1.4 NA oil-

477 immersion objective (Quorum Technologies, Guelph, ON). Live-cell imaging was performed

478 using environmental chamber set to $5 \% \mathrm{CO}_{2}$ and $37^{\circ} \mathrm{C}$ in complete cell-specific medium. Standard

479 excitation and emission filter sets and lasers were used for all fluorophores. RAW and HeLa cells, 
480 unless otherwise indicated, were imaged as z-projections of 45-55 z-planes with $0.3 \mu \mathrm{m}$ distance

481 between each plane, or 20-30 z-planes with $0.3 \mu \mathrm{m}$ distance between each plane for RPE cells, as

482 acquired by spinning disc confocal microscopy. For time-lapse imaging, RAW cells were imaged

483 using single, mid-section z-plane every $4 \mathrm{~s}$ for $3 \mathrm{~min}$. RPE cells were imaged using single, mid-

484 section z-plane every $8 \mathrm{~s}$ for $6 \mathrm{~min}$. Clathrin-eGFP expressing RPE cells were imaged every 2 min

485 for $40 \mathrm{~min}$.

486

\section{Detection of ROS production}

488 For determining intracellular net ROS production, we incubated RAW 264.7 macrophages with 5

$489 \mu \mathrm{M}$ of the cell-permeable redox sensitive dye, CellROX Green (Thermo Fisher Scientific), for 30

$490 \min$ at $37^{\circ} \mathrm{C}$ with $5 \% \mathrm{CO}_{2}$ in the dark during treatment with various $\mathrm{ROS}$ producing agents.

491 Cells were washed twice with PBS followed by replenishment with complete media and

492 imaging. To detect specific intracellular ROS, we used several probes: hydroxylphenyl

493 fluorescein to detect hydroxyl radical and peroxynitrite (HPF; Thermo Fisher Scientific),

494 MitoSOX Red for mitochondrial superoxide (Thermo Fisher Scientific), Biotracker Si-DMA for

495 singlet oxygen (Millipore Sigma), and ROS-ID detection kit (Enzo Life Sciences) for general

496 superoxide. After treatment with ROS inducers, cells were washed with PBS 3x before adding

497 these fluorescent probes. Cells were incubated with $5 \mu \mathrm{M}$ Mitosox Red for $10 \mathrm{~min}$ at $37^{\circ} \mathrm{C}$ with

$4985 \% \mathrm{CO}_{2}$ in the dark, or $100 \mathrm{nM}$ Si-DMA or $10 \mu \mathrm{M}$ HPF for 45 minutes. For ROS-ID $0.06 \mathrm{nM}$

499 ROS-ID was added $1 \mathrm{~h}$ before, incubated at $37^{\circ} \mathrm{C}$ with $5 \% \mathrm{CO}_{2}$ in the dark, followed by washing

500 with PBS and adding ROS inducers. After treatment with ROS probes or inducers, cells were 
washed 3x PBS and supplemented with probe specific media. All experiments were imaged using live-cell spinning disc confocal microscopy as described.

\section{Immunofluorescence and F-actin imaging}

504 Following experimentation, cells were fixed for 15 min with 4\% (v/v) paraformaldehyde in PBS,

505 permeabilized for 10 min with $0.1 \%$ Triton X-100 (v/v) in PBS, and then blocked with 3\% BSA

506 (v/v) in PBS. Subsequently, cells were incubated with mouse monoclonal antibody against $\alpha-$

507 tubulin (1:200; Sigma-Aldrich), followed by incubation with donkey Dylight-conjugated

508 polyclonal antibody against mouse $\operatorname{IgG}(1: 1000$; Bethyl), and samples were then mounted in Dako

509 mounting media for subsequent imaging. Alternatively, lysosomes were labelled with Alexa ${ }^{488}$

510 conjugated dextran as before, followed by fixation for $15 \mathrm{~min}$ with $4 \%$ (v/v) paraformaldehyde,

511 permeabilized for $10 \mathrm{~min}$ with $10 \mu \mathrm{g} / \mathrm{ml}$ digitonin (Promega, Madison, WI), and blocked with 3\%

512 BSA (v/v), all solutions in PBS. Cells were then stained for F-actin with fluorescent-phalloidin

513 (ThermoFisher Scientific).

\section{Lysosome damage detected by galectin-3-GFP}

515 RAW cells were seeded in DMEM supplemented with $5 \% \mathrm{FBS}$ for $24 \mathrm{~h}$ at $37{ }^{\circ} \mathrm{C}$ in $5 \% \mathrm{CO}_{2}$. Cells

516 were transfected with Galectin-3-GFP plasmid (0.5 $\mu \mathrm{g})$ using FuGene HD (Promega, Madison,

517 WI) with a ratio of $3: 1$ for $24 \mathrm{~h}$ at $37{ }^{\circ} \mathrm{C}$ in $5 \% \mathrm{CO}_{2}$. Post-transfection, cells were treated with 1

$518 \mathrm{mM} \mathrm{H}_{2} \mathrm{O}_{2}$ for $40 \mathrm{~min}, 1 \mu \mathrm{M}$ rotenone for $60 \mathrm{~min}$ or for $2 \mathrm{~h}$ with $0.5 \mathrm{mM}$ L-leucyl-L-leucine methyl

519 ester (LLOMe; L7393, Sigma-Aldrich). 


\section{Image analysis}

522 To determine lysosome number, individual lysosome volume and total cellular lysosome volume,

523 we used Volocity (Volocity 6.3.0) particle detection and volumetric tools. Z-stack images were

524 imported into Volocity and a signal threshold was applied at 2x the average cytosolic fluorescence

525 intensity. Particles were defined as being greater than $0.3 \mu \mathrm{m}^{3}$ for inclusion into the analysis, and

526 if necessary, a watershed function was applied to split lysosome aggregates caused by

527 thresholding. Regions of interest were drawn surrounding individual cells for cell-to-cell analysis.

528 Lysosome speed, track length, and displacement were assessed using Imaris (BitPlane, Concord,

529 MA) with 'ImarisTrackLineage' module.

To determine the level of membrane-bound RILP-C33 and Arl8b, we estimated the

531 membrane-bound to cytosolic ratio of fluorescently-tagged proteins. Using ImageJ, lines that were

532 3-pixel wide by 20-40-pixel long were assigned to areas of transfected cells using a predetermined

533 grid to avoid bias but excluding the nucleus. Plot profiles were then obtained, exported into an

534 Excel spreadsheet, values were arranged according to fluorescence intensity, and the ratio

535 calculated for highest 10 pixels over lowest 10 pixels along the length of the line $\left(\mathrm{F}_{\mathrm{H}} / \mathrm{F}_{\mathrm{L}}\right.$

536 fluorescence ratio); the expectation is that values approximate to 1 represent low membrane signal

537 due to mostly cytosolic signal, while ratio values greater than 1 represent signal that localizes to

538 punctate structures relative to cytosol (Chintaluri et al., 2018).

For determination of clathrin-GFP on lysosomes, RPE cells stably expressing clathrin

540 heavy chain-eGFP were loaded with Alexa ${ }^{546}$-conjugated dextran and treated with apilimod,

541 followed by imaging with spinning disc confocal microscope. Image analysis was performed

542 using Image J by thresholding Alexa ${ }^{546}$-conjugated dextran signal and generating a mask, which

543 was then applied to the green (clathrin) channel to determine the GFP fluorescence intensity on

544 regions marked by dextran signal. Regions of interest within the cytosol and the extracellular 
545 space were drawn to respectively obtain mean cytosolic fluorescence intensity and background.

546 These values were then used to calculate the ratio of lysosome-to-cytosol clathrin-eGFP. Similar

547 approach was employed to determine Fluo-4AM intensity for dextran Alexa ${ }^{546}$ lysosomal

548 structures over cytosolic Fluo-4AM to obtain lysosome-to-cytosol Fluo-4AM intensity ratio. To

549 determine the fluorescence of intracellular CellROX Green or other ROS probes, images were

550 imported onto Volocity (Volocity 6.3.0) or ImageJ, regions of interest were drawn around cell,

551 and mean fluorescence intensity per cell was recorded and background-corrected. For galectin-3-

552 GFP analysis, images were imported into ImageJ, background-corrected, and then thresholding

553 was applied to each individual transfected cell (25-30 cells per condition) to identify galectin-3-

554 GFP puncta. Particles ranging between 50-1000 $\mu^{2}$ were then counted, with the assumption that

555 smaller size particles corresponded to noise.

556 To assess microtubule structure, we sought to use several measures as proxies for

557 microtubule alteration under different treatments. Single-plane images were converted to 8-bit 558 images through ImageJ followed by application of fluorescence intensity threshold to select

559 microtubules. Images were converted to binary and filaments analyzed through "skeleton" and

560 "Analyzeskeleton". Total number of microtubules junctions, where junctions represent

561 filamentous pixels from where two or more microtubule branches arise, total number of

562 microtubule branches and average microtubule branch length were scored and collected for data

563 analysis. Alternatively, RPE cell microtubule structure was analyzed through applying binary filter

564 to fluorescent microtubules, followed by watershed segmentation to segregate microtubules into

565 areas of tubulin patches with the expectation that depolymerized microtubules pool into large

566 patches compared to intact tubulin. 
Image contrast enhancement was performed with Adobe Photoshop CS (Adobe Systems,

568 San Jose, CA) or ImageJ without changing relative signals and applied after quantification. Adobe

569 Illustrator CS (Adobe Systems) was used for constructing figures.

\section{Lysosome fractionation}

572 RAW 264.7 cells were grown and used according to manufacturer's instructions to obtain

573 membrane fractions by differential sedimentation ultracentrifugation using a density gradient

574 (Lysosome Isolation Kit, Sigma-Aldrich, LYSISO1). Briefly, cells were lysed and homogenates

575 centrifuged $1,000 \mathrm{xg}$ for $10 \mathrm{~min}$ at $4{ }^{\circ} \mathrm{C}$ to separate unbroken cells and debris from cytoplasmic

576 membranes. The supernatant was further centrifuged at $20,000 \mathrm{xg}$ for $20 \mathrm{~min}$ at $4{ }^{\circ} \mathrm{C}$ to pellet

577 lysosomes and other organelles. The pellet was reconstituted with Optiprep density gradient

578 medium $(60 \%$ (w/v) solution of iodixanol in water and sucrose) and loaded onto of a step-wise

579 sucrose gradient as described by the manufacturer and subjected to ultracentrifugation at 150,000

$580 \mathrm{x} g$ for $4 \mathrm{~h}$ at $4{ }^{\circ} \mathrm{C}$ using SW50.1 rotor (Beckman Coulter, Mississauga, ON). Fractions were then

581 collected and subject to denaturation with Laemmli buffer until further use.

\section{Membrane fractionation}

584 RAW cells were lysed in $200 \mu$ ice cold homogenization buffer $(3 \mathrm{mM}$ imidazole, $250 \mathrm{mM}$

585 sucrose, $0.5 \mathrm{mM}$ EDTA, $\mathrm{pH} 7.4$ with protease inhibitor cocktail). Cells were homogenized by

586 passing 10x though a 25-gauge needle, then lysates were sequentially centrifuged at $3000 \times g$ for

$58710 \mathrm{~min}$ at $4{ }^{\circ} \mathrm{C}$ and $7,000 \mathrm{xg}$ for $10 \mathrm{~min}$ at $4{ }^{\circ} \mathrm{C}$ to clear supernantants. Supernatants were then 588 further centrifuged at 100,000 x $g$ using SORVALL wX+ULTRA-centrifuge (Thermo Scientific)

589 for $30 \mathrm{~min}$ at $4^{\circ} \mathrm{C}$ to separate cytosol and membranes. Next, the pellets were resuspended in $0.5 \%$ 
590 digitonin in solubilization buffer $(50 \mathrm{mM} \mathrm{NaCl}, 50 \mathrm{mM}$ imidazole, $2.5 \mathrm{mM}$ 6-aminohexanoic acid,

5912 mM EDTA, $\mathrm{pH} \sim 7)$ to obtain membrane-bound materials.

\section{Western Blotting}

593 For whole-cell lysates in 2x Laemmli buffer, cells were passed six times through 27-gauge needle,

594 heated. Cell lysates or cell fractions were resolved through SDS-PAGE with 10\% acrylamide

595 resolving gel. Proteins were then transferred to a PVDF membrane, blocked and incubated with

596 primary and HRP-conjugated secondary antibodies in Tris-buffered saline containing 5\% skimmed

597 milk and 0.1\% Tween-20. Clarity enhanced chemiluminescence (Bio-Rad Laboratories,

598 Mississauga, ON) was used to visualize proteins with ChemiDoc Touch Imaging system (Bio-

599 Rad). Protein quantification was performed using Image Lab software (Bio-Rad) by sequentially

600 normalizing against a loading control and against vehicle-treated condition. We used rabbit

601 polyclonal antibodies against VAPB (1:3000, HPA013144, Sigma-Aldrich) and vinculin (1:1000,

602 4650, Cell Signalling Technologies), rabbit XP® monoclonal antibodies against Rab7 (1:100,

603 D95F2, Cell Signalling Technologies), mouse monoclonal antibodies against clathrin heavy chain

604 (1:500, sc-12734, Santa Cruz Biotechnology), Arl8a/b (1:500, clone H8, Santa Cruz 605 Biotechnology), and ATP5A (1:2000, ab14748, Abcam), rat monoclonal antibodies against

606 LAMP1 (1:200-1:500, 1D4B, Developmental Studies Hybridoma Bank, Iowa City, IO or Santa

607 Cruz Biotechnology), and goat polyclonal antibody against dynamin 2 (1:1000, sc-6400, Santa

608 Cruz Biotechnology). Secondary antibodies were raised in donkey (Bethyl) and HRP-conjugated. 


\section{Phosphoinositide labelling with ${ }^{\mathbf{3}} \mathbf{H}$-myo-inositol and HPLC-coupled}

611 flow scintillation

612 RAW cells were incubated for $24 \mathrm{~h}$ with inositol-free DMEM (MP Biomedica, CA) containing 10

$613 \mu \mathrm{Ci} / \mathrm{ml} \quad m y o-\left[2-{ }^{3} \mathrm{H}(\mathrm{N})\right]$ inositol (Perkin Elmer, MA), $1 \mathrm{X}$ insulin-transferrin-selenium-

614 ethanolamine (Gibco), 10\% dialyzed FBS (Gibco), 4 mM L-glutamine (Sigma-Aldrich) and 20

$615 \mathrm{mM}$ HEPES (Gibco). Cells were then treated with rotenone, $\mathrm{H}_{2} \mathrm{O}_{2}$ and/or apilimod as indicated.

616 Cells were lysed and lipids precipitated with $600 \mu \mathrm{l}$ of $4.5 \%$ perchloric acid (v/v) for $15 \mathrm{~min}$ on

617 ice, collected by scraping and pellet obtained at $12000 \mathrm{x}$ for $10 \mathrm{~min}$. Then, $1 \mathrm{ml}$ of $0.1 \mathrm{M}$ EDTA

618 was used to wash pellets followed by resuspension in $50 \mu \mathrm{l}$ water. This was followed by $500 \mu \mathrm{l}$ of

619 methanol/40\% methylamine/1-butanol [45.7\% methanol: 10.7\% methylamine: 11.4\% 1-butanol

620 (v/v)] used for $50 \mathrm{~min}$ at $53{ }^{\circ} \mathrm{C}$ to deacylate phospholipids. Sample pellets were vaccum-dried and

621 washed twice in $300 \mu \mathrm{l}$ water with vaccum-drying. Deacylated phospholipids were extracted from

622 dried sample pellets by resuspending pellet in $450 \mu$ water and $300 \mu$ l 1-butanol/ethyl ether/ethyl

623 formate (20:4:1), vortexing $5 \mathrm{~min}$, followed by centrifugation $12000 \mathrm{xg}$ for 2 min and then the

624 bottom aqueous layer was collected. Extraction was performed three times followed by vaccum-

625 drying the aqueous layer and resuspending lipids in $50 \mu \mathrm{l}$ water. For all treatment samples, equal

$626{ }^{3} \mathrm{H}$ counts were loaded and separated by HPLC (Agilent Technologies, Mississauga, ON) through

6274.6 x 250-mm anion exchange column (Phenomenex, Torrance, CA) using a $1 \mathrm{ml} / \mathrm{min}$ flow rate

628 with a gradient set with water (buffer A) and $1 \mathrm{M}\left(\mathrm{NH}_{4}\right)_{2} \mathrm{HPO}_{4}, \mathrm{pH} 3.8$ (phosphoric acid adjusted)

629 (buffer B) as follows: 0\% B for $5 \mathrm{~min}, 0$ to $2 \% \mathrm{~B}$ for 15 minutes, $2 \%$ B for 80 minutes, 2 to $10 \%$

630 B for 20 minutes, 10\% B for 30 minutes, 10 to $80 \%$ B for 10 minutes, $80 \%$ B for 5 minutes, 80 to

$6310 \%$ B for 5 minutes. Radiolabel signal was detected with a 1:2 ratio of eluate to scintillant

632 (LabLogic, Brandon, FL) in a $\beta$-RAM 4 (LabLogic) and analyzed by Laura 4 software. Each 
633 phosphoinositide species detected was normalized against the parent phosphatidylinositol peak as

634 described in (Ho et al., 2016).

635

\section{Phagocytosis particle preparation and phagosome maturation assays} pZsGreen-containing bacteria were grown at $37{ }^{\circ} \mathrm{C}$ in Lysogeny Broth (LB), supplemented with

$6381 \%$ glucose to suppress leaky ZsGreen expression, and $100 \mu \mathrm{g} / \mathrm{mL}$ ampicillin (LB Growth Media).

639 To produce ZsGreen-expressing bacteria, bacteria cultures were grown overnight in liquid LB

640 Growth Media. The bacteria culture was then subcultured 1:100 in LB supplemented with

641 ampicillin and without glucose (LB Expression Media) and incubated at $37{ }^{\circ} \mathrm{C}$ to mid-log growth

642 phase. Isopropylthio- $\beta$-galactoside was added into the subculture to a final concentration of 100

$643 \mu \mathrm{M}$, and the subculture was incubated for another 3 hours. Bacteria were washed with PBS, then

644 fixed with $4 \%$ PFA, and stored at $4{ }^{\circ} \mathrm{C}$ in PFA. Prior to use, fixed bacteria were washed with PBS

645 to remove PFA.

RAW macrophages at 30 to $60 \%$ confluence were treated with $1 \mathrm{mM} \mathrm{H}_{2} \mathrm{O}_{2}$ or $0.1 \% \mathrm{ddH}_{2} \mathrm{O}$

647 (vehicle control) for $1 \mathrm{~h}$. Subsequently, $8.0 \times 10^{7}$ bacteria $(0.1 \mathrm{OD} \times 1 \mathrm{~mL})$ were introduced to 648 macrophages and centrifuged at $400 \mathrm{x} \mathrm{g}$ for 5 minutes to synchronize phagocytosis. Macrophages

649 were incubated for 20 minutes in the presence of $\mathrm{H}_{2} \mathrm{O}_{2}$ or $\mathrm{ddH}_{2} \mathrm{O}$ before washing with PBS and 650 incubating in media containing $\mathrm{H}_{2} \mathrm{O}_{2}$ or $\mathrm{ddH}_{2} \mathrm{O}$ for 40 minutes. Except for PBS wash, macrophage

651 exposure to $\mathrm{H}_{2} \mathrm{O}_{2}$ was uninterrupted. Macrophages were washed with PBS then fixed with $4 \%$

652 PFA. Cells were then incubated in $1 \% \mathrm{w} / \mathrm{v}$ glycine to quench PFA. Cells were then blocked with

$6531 \%$ Bovine Serum Albumin (BSA), then external bacteria were immunolabeled with rabbit anti-

654 E. coli antibodies (1:100, Bio-Rad Antibodies, 4329-4906), followed by DyLight 650-conjugated

655 donkey anti-rabbit IgG antibodies (1:1000, Bethyl Laboratories, Inc., A120-208D5). Cells were 
656 then permeabilized with ice-cold methanol and blocked with 1\% BSA. LAMP-1 lysosomal marker

657 protein was immunolabeled with rat anti-LAMP-1 antibodies (1:100, 1D4B, Developmental

658 Studies Hybridoma Bank, Iowa City, IO), followed by DyLight 550-conjugated donkey anti-rat

659 IgG antibodies (1:1000, Bethyl Laboratories, Inc., A110-337D3). Coverslips were mounted with

660 Dako Fluorescence Mounting Medium (Agilent, S302380-2) for imaging.

661 FIJI was used for image processing and quantitative image analysis of phagosome 662 maturation. Internal bacteria masks were produced by applying a subtraction mask using external

663 bacteria signal. "Noise" particles defined as being a few pixels in size were removed manually.

664 The internal bacteria mask was converted to binary and dilated to reach the edges of the

665 phagosomes (LAMP1 signal). LAMP-1 signal colocalized to the internal bacteria mask was

666 analyzed cell-by-cell, and the mean LAMP-1 fluorescence intensity per cell was obtained.

\section{Statistical analysis}

669 All experiments were performed independently at least three times. Respective figure legends

670 indicate number of cells/samples assessed, mean, standard error of mean (s.e.m.) and number of

671 independent experiments. For analysing significant difference between various treatment groups,

672 we used unpaired Student's t-test when comparing two groups only or one-way ANOVA test when

673 comparing multiple treatment conditions in non-normalized controls. Tukey's post hoc test

674 coupled to ANOVA tests was used to evaluate pairwise conditions. Statistical significance was

675 defined as $P>0.05$. Software used for analysis was GraphPad Prism 8. 


\section{References}

678 1. Luzio JP, Rous BA, Bright NA, Pryor PR, Mullock BM, Piper RC. Lysosome-endosome fusion and lysosome biogenesis. J Cell Sci. 2000;113 ( Pt 9: 1515-24. Available: http://www.ncbi.nlm.nih.gov/pubmed/10751143

2. Luzio JP, Pryor PR, Bright NA. Lysosomes: fusion and function. Nat Rev Mol Cell Biol. 2007;8: 622-32. doi:10.1038/nrm2217

3. Pu J, Guardia CM, Keren-Kaplan T, Bonifacino JS. Mechanisms and functions of lysosome positioning. J Cell Sci. Company of Biologists; 2016;129: 4329-4339. doi:10.1242/jcs.196287

4. Bissig C, Hurbain I, Raposo G, van Niel G. PIKfyve activity regulates reformation of terminal storage lysosomes from endolysosomes. Traffic. 2017;18: 747-757. doi:10.1111/tra.12525

5. Bright NA, Reaves BJ, Mullock BM, Luzio JP. Dense core lysosomes can fuse with late endosomes and are re-formed from the resultant hybrid organelles. J Cell Sci. 1997;110 ( Pt 1: 2027-40. Available: http://www.ncbi.nlm.nih.gov/pubmed/9378754

6. Bright NA, Davis LJ, Luzio JP. Endolysosomes Are the Principal Intracellular Sites of Acid Hydrolase Activity. Curr Biol. Elsevier; 2016;26: 2233-45. doi:10.1016/j.cub.2016.06.046

7. Perou CM, Leslie JD, Green W, Li L, Ward DM, Kaplan J. The Beige/Chediak-Higashi syndrome gene encodes a widely expressed cytosolic protein. J Biol Chem. 1997;272: 29790-4. Available: http://www.ncbi.nlm.nih.gov/pubmed/9368050

8. Bright NA, Gratian MJ, Luzio JP. Endocytic delivery to lysosomes mediated by concurrent fusion and kissing events in living cells. Curr Biol. 2005;15: 360-365. doi:10.1016/j.cub.2005.01.049

9. Duclos S, Corsini R, Desjardins M. Remodeling of endosomes during lysosome biogenesis involves "kiss and run" fusion events regulated by rab5. J Cell Sci. 2003;116: 907-18. Available: http://www.ncbi.nlm.nih.gov/pubmed/12571288

10. Saffi GT, Botelho RJ. Lysosome Fission: Planning for an Exit [Internet]. Trends in Cell Biology. 2019. pp. 635-646. doi:10.1016/j.tcb.2019.05.003

11. Khatter D, Raina VB, Dwivedi D, Sindhwani A, Bahl S, Sharma M. The small GTPase Arl8b regulates assembly of the mammalian HOPS complex on lysosomes. J Cell Sci. 2015;128: 1746-61. doi:10.1242/jcs.162651

12. Wang T, Ming Z, Xiaochun W, Hong W. Rab7: Role of its protein interaction cascades in endo-lysosomal traffic [Internet]. Cellular Signalling. 2011. pp. 516-521. doi:10.1016/j.cellsig.2010.09.012

13. Cantalupo G, Alifano P, Roberti V, Bruni CB, Bucci C. Rab-interacting lysosomal protein (RILP): The Rab7 effector required for transport to lysosomes. EMBO J. 2001;20: 683693. doi:10.1093/emboj/20.4.683

14. Pankiv S, Alemu E a., Brech A, Bruun J-AA, Lamark T, Øvervatn A, et al. FYCO1 is a Rab7 effector that binds to LC3 and PI3P to mediate microtubule plus end - Directed vesicle transport. J Cell Biol. 2010;188: 253-269. doi:10.1083/jcb.200907015

15. Rosa-Ferreira C, Munro S. Arl8 and SKIP Act Together to Link Lysosomes to Kinesin-1. Dev Cell. 2011;21: 1171-1178. doi:10.1016/j.devcel.2011.10.007

16. Khatter D, Sindhwani A, Sharma M. Arf-like GTPase Arl8: Moving from the periphery to the center of lysosomal biology. Cell Logist. 2015;5: e1086501. doi:10.1080/21592799.2015.1086501

17. Luzio JP, Parkinson MDJ, Gray SR, Bright NA. The delivery of endocytosed cargo to 
lysosomes. Biochem Soc Trans. 2009;37: 1019-1021. doi:10.1042/BST0371019

18. Cao Q, Zhong XZ, Zou Y, Murrell-Lagnado R, Zhu MX, Dong XP. Calcium release through P2X4 activates calmodulin to promote endolysosomal membrane fusion. J Cell Biol. 2015;209: 879-894. doi:10.1083/jcb.201409071

19. Cao Q, Yang Y, Zhong XZ, Dong XP. The lysosomal Ca2+release channel TRPML1 regulates lysosome size by activating calmodulin. J Biol Chem. 2017;292: 8424-8435. doi:10.1074/jbc.M116.772160

20. Fang X, Zhou J, Liu W, Duan X, Gala U, Sandoval H, et al. Dynamin Regulates Autophagy by Modulating Lysosomal Function. J Genet Genomics. 2016;43: 77-86. doi:10.1016/j.jgg.2015.10.005

21. Hong NH, Qi A, Weaver AM. PI(3,5)P2 controls endosomal branched actin dynamics by regulating cortactin-Actin interactions. $J$ Cell Biol. 2015;210: 753-769. doi:10.1083/jcb.201412127

22. Renvoisé B, Chang J, Singh R, Yonekawa S, FitzGibbon EJ, Mankodi A, et al. Lysosomal abnormalities in hereditary spastic paraplegia types SPG15 and SPG11. Ann Clin Transl Neurol. 2014;1: 379-389. doi:10.1002/acn3.64

23. Rong Y, Liu M, Ma L, Du W, Zhang H, Tian Y, et al. Clathrin and phosphatidylinositol4,5-bisphosphate regulate autophagic lysosome reformation. Nat Cell Biol. 2012;14: 924934. doi:10.1038/ncb2557

24. Traub LM, Bannykh SI, Rodel JE, Aridor M, Balch WE, Kornfeld S. AP-2-containing clathrin coats assemble on mature lysosomes. J Cell Biol. 1996;135: 1801-14. Available: http://www.ncbi.nlm.nih.gov/pubmed/8991092

25. Li X, Rydzewski N, Hider A, Zhang X, Yang J, Wang W, et al. A molecular mechanism to regulate lysosome motility for lysosome positioning and tubulation. Nat Cell Biol. 2016;18: 404-417. doi:10.1038/ncb3324

26. Yang Y, Xu M, Zhu X, Yao J, Shen B, Dong X-P. Lysosomal Ca2+ release channel TRPML1 regulates lysosome size by promoting mTORC1 activity. Eur J Cell Biol. 2019;98: 116-123. doi:10.1016/j.ejcb.2019.05.001

27. McCartney AJ, Zhang Y, Weisman LS. Phosphatidylinositol 3,5-bisphosphate: low abundance, high significance. Bioessays. 2014;36: 52-64. doi:10.1002/bies.201300012

28. Shisheva A, Sbrissa D, Ikonomov O. Plentiful PtdIns5P from scanty PtdIns(3,5)P 2 or from ample PtdIns? PIKfyve-dependent models: Evidence and speculation (response to: DOI 10.1002/bies.201300012). BioEssays. 2015;37: 267-277. doi:10.1002/bies.201400129

29. Chow CY, Zhang Y, Dowling JJ, Jin N, Adamska M, Shiga K, et al. Mutation of FIG4 causes neurodegeneration in the pale tremor mouse and patients with CMT4J. Nature. 2007;448: 68-72. doi:10.1038/nature05876

30. Choy CH, Saffi G, Gray MA, Wallace C, Dayam RM, Ou Z-YA, et al. Lysosome enlargement during inhibition of the lipid kinase PIKfyve proceeds through lysosome coalescence. J Cell Sci. 2018; jcs.213587. doi:10.1242/jcs.213587

31. Sbrissa D, Ikonomov OC, Fu Z, Ijuin T, Gruenberg J, Takenawa T, et al. Core protein machinery for mammalian phosphatidylinositol 3,5-bisphosphate synthesis and turnover that regulates the progression of endosomal transport: Novel Sac phosphatase joins the ArPIKfyve-PIKfyve complex. J Biol Chem. 2007;282: 23878-23891. doi:10.1074/jbc.M611678200

32. Gopaldass N, Fauvet B, Lashuel H, Roux A, Mayer A. Membrane scission driven by the PROPPIN Atg18. EMBO J. 2017;36: e201796859. doi:10.15252/embj.201796859 
33. Chen Y, Azad MB, Gibson SB. Superoxide is the major reactive oxygen species regulating autophagy. Cell Death Differ. 2009;16: 1040-1052. doi:10.1038/cdd.2009.49

34. Dizdaroglu M, Jaruga P. Mechanisms of free radical-induced damage to DNA. Free Radic Res. 2012;46: 382-419. doi:10.3109/10715762.2011.653969

35. Finkel T. From Sulfenylation to Sulfhydration: What a Thiolate Needs to Tolerate. Sci Signal. 2012;5: pe10-pe10. doi:10.1126/scisignal.2002943

774

36. Ristow M, Schmeisser S. Extending life span by increasing oxidative stress. Free Radic Biol Med. 2011;51: 327-336. doi:10.1016/j.freeradbiomed.2011.05.010

37. Schieber M, Chandel NS. ROS function in redox signaling and oxidative stress. Curr Biol. NIH Public Access; 2014;24: R453-62. doi:10.1016/j.cub.2014.03.034

38. Marengo B, Nitti M, Furfaro AL, Colla R, Ciucis C De, Marinari UM, et al. Redox homeostasis and cellular antioxidant systems: Crucial players in cancer growth and therapy [Internet]. Oxidative Medicine and Cellular Longevity. Hindawi Limited; 2016. p. 6235641. doi:10.1155/2016/6235641

39. Icha J, Weber M, Waters JC, Norden C. Phototoxicity in live fluorescence microscopy, and how to avoid it. BioEssays. 2017;39: 1700003. doi:10.1002/bies.201700003

40. Heinz S, Freyberger A, Lawrenz B, Schladt L, Schmuck G, Ellinger-Ziegelbauer H. Mechanistic Investigations of the Mitochondrial Complex I Inhibitor Rotenone in the Context of Pharmacological and Safety Evaluation. Sci Rep. Nature Publishing Group; 2017;7: 45465. doi:10.1038/srep45465

41. Kamencic H, Lyon A, Paterson PG, Juurlink BHJ. Monochlorobimane Fluorometric Method to Measure Tissue Glutathione. Anal Biochem. 2000;286: 35-37. doi:10.1006/abio.2000.4765

42. Padgaonkar VA, Leverenz VR, Bhat A V, Pelliccia SE, Giblin FJ. Thioredoxin reductase activity may be more important than GSH level in protecting human lens epithelial cells against UVA light. Photochem Photobiol. NIH Public Access; 2015;91: 387-96. doi:10.1111/php.12404

43. Aldini G, Altomare A, Baron G, Vistoli G, Carini M, Borsani L, et al. N-Acetylcysteine as an antioxidant and disulphide breaking agent: the reasons why. Free Radic Res. 2018;52: 751-762. doi:10.1080/10715762.2018.1468564

44. Lee SR, Kwon KS, Kim SR, Rhee SG. Reversible inactivation of protein-tyrosine phosphatase 1B in A431 cells stimulated with epidermal growth factor. J Biol Chem. 1998;273: 15366-72. Available: http://www.ncbi.nlm.nih.gov/pubmed/9624118

45. Leslie NR, Bennett D, Lindsay YE, Stewart H, Gray A, Downes CP. Redox regulation of PI 3-kinase signalling via inactivation of PTEN. EMBO J. European Molecular Biology Organization; 2003;22: 5501-5510. doi:10.1093/emboj/cdg513

46. Ho CY, Choy CH, Botelho RJ. Radiolabeling and Quantification of Cellular Levels of Phosphoinositides by High Performance Liquid Chromatography-coupled Flow Scintillation. J Vis Exp. 2016; e53529-e53529. doi:10.3791/53529

47. Weaver BA. How Taxol/paclitaxel kills cancer cells. Mol Biol Cell. American Society for Cell Biology; 2014;25: 2677-81. doi:10.1091/mbc.E14-04-0916

48. Maejima I, Takahashi A, Omori H, Kimura T, Takabatake Y, Saitoh T, et al. Autophagy sequesters damaged lysosomes to control lysosomal biogenesis and kidney injury. EMBO J. EMBO J; 2013;32: 2336-2347. doi:10.1038/emboj.2013.171

49. Chauhan S, Kumar S, Jain A, Ponpuak M, Mudd MH, Kimura T, et al. TRIMs and Galectins Globally Cooperate and TRIM16 and Galectin-3 Co-direct Autophagy in Endomembrane 
Damage Homeostasis. Dev Cell. 2016;39: 13-27. doi:10.1016/j.devcel.2016.08.003

50. Dong X, Shen D, Wang X, Dawson T, Li X, Zhang Q, et al. PI(3,5)P(2) controls membrane trafficking by direct activation of mucolipin $\mathrm{Ca}(2+)$ release channels in the endolysosome. Nat Commun. 2010;1: 38. doi:10.1038/ncomms1037

51. Zhang X, Cheng X, Yu L, Yang J, Calvo R, Patnaik S, et al. MCOLN1 is a ROS sensor in lysosomes that regulates autophagy. Nat Commun. 2016;7: 12109. doi:10.1038/ncomms12109

52. Dayam RM, Saric A, Shilliday RE, Botelho RJ. The Phosphoinositide-Gated Lysosomal Ca2+ Channel, TRPML1, Is Required for Phagosome Maturation. Traffic. 2015;16: 10101026. doi:10.1111/tra.12303

53. Gee KR, Brown KA, Chen WNU, Bishop-Stewart J, Gray D, Johnson I. Chemical and physiological characterization of fluo-4 Ca2+-indicator dyes. Cell Calcium. Elsevier Ltd; 2000;27: 97-106. doi:10.1054/ceca.1999.0095

54. Boutry M, Branchu J, Lustremant C, Pujol C, Pernelle J, Matusiak R, et al. Inhibition of Lysosome Membrane Recycling Causes Accumulation of Gangliosides that Contribute to Neurodegeneration. Cell Rep. 2018;23: 3813-3826. doi:10.1016/j.celrep.2018.05.098

55. Elkin SR, Oswald NW, Reed DK, Mettlen M, MacMillan JB, Schmid SL. Ikarugamycin: A Natural Product Inhibitor of Clathrin-Mediated Endocytosis. Traffic. Blackwell Munksgaard; 2016;17: 1139-1149. doi:10.1111/tra.12425

56. Von Kleist L, Stahlschmidt W, Bulut H, Gromova K, Puchkov D, Robertson MJ, et al. Role of the clathrin terminal domain in regulating coated pit dynamics revealed by small molecule inhibition. Cell. Cell Press; 2011;146: 471-484. doi:10.1016/j.cell.2011.06.025

57. Hoyer MJ, Chitwood PJ, Ebmeier CC, Striepen JF, Qi RZ, Old WM, et al. A Novel Class of ER Membrane Proteins Regulates ER-Associated Endosome Fission. Cell. 2018;175: 254-265.e14. doi:10.1016/j.cell.2018.08.030

58. Bissig C, Croisé P, Heiligenstein X, Hurbain I, Lenk GM, Kaufman E, et al. The PIKfyve complex regulates the early melanosome homeostasis required for physiological amyloid formation. J Cell Sci. 2019;132: jcs229500. doi:10.1242/jcs.229500

59. Hasegawa J, Iwamoto R, Otomo T, Nezu A, Hamasaki M, Yoshimori T. Autophagosomelysosome fusion in neurons requires INPP5E, a protein associated with Joubert syndrome. EMBO J. European Molecular Biology Organization; 2016;35: 1853-67. doi:10.15252/embj.201593148

60. Krajcovic M, Krishna S, Akkari L, Joyce JA, Overholtzer M. mTOR regulates phagosome and entotic vacuole fission. Klumperman J, editor. Mol Biol Cell. 2013;24: 3736-3745. doi:10.1091/mbc.E13-07-0408

61. Gan Q, Wang X, Zhang Q, Yin Q, Jian Y, Liu Y, et al. The amino acid transporter SLC36.1 cooperates with PtdIns3P 5-kinase to control phagocytic lysosome reformation. J Cell Biol. Rockefeller University Press; 2019;218: 2619-2637. doi:10.1083/JCB.201901074

62. Cooke FT, Dove SK, McEwen RK, Painter G, Holmes a B, Hall MN, et al. The stressactivated phosphatidylinositol 3-phosphate 5-kinase Fab1p is essential for vacuole function in S. cerevisiae. Curr Biol. 1998;8: 1219-22. doi:10.1016/S0960-9822(07)00513-1

63. Jin N, Jin Y, Weisman LS. Early protection to stress mediated by CDK-dependent PI3,5P 2 signaling from the vacuole/lysosome. J Cell Biol. Rockefeller University Press; 2017;216: 2075-2090. doi:10.1083/jcb.201611144

64. Mackeh R, Lorin S, Ratier A, Mejdoubi-Charef N, Baillet A, Bruneel A, et al. Reactive oxygen species, AMP-activated protein kinase, and the transcription cofactor p300 regulate 
902

\section{3}

\section{Figure legends}

904

$\alpha$-tubulin acetyltransferase-1 ( $\alpha$ TAT-1/MEC-17)-dependent microtubule hyperacetylation during cell stress. J Biol Chem. American Society for Biochemistry and Molecular Biology; 2014;289: 11816-28. doi:10.1074/jbc.M113.507400

65. Debattisti V, Gerencser AA, Saotome M, Das S, Hajnóczky G. ROS Control Mitochondrial Motility through p38 and the Motor Adaptor Miro/Trak. Cell Rep. Elsevier B.V.; 2017;21: 1667-1680. doi:10.1016/j.celrep.2017.10.060

66. Valen G, Sondén A, Vaage J, Malm E, Kjellström BT. Hydrogen peroxide induces endothelial cell atypia and cytoskeleton depolymerization. Free Radic Biol Med. Elsevier Inc.; 1999;26: 1480-1488. doi:10.1016/S0891-5849(99)00009-X

67. Friedman JR, DiBenedetto JR, West M, Rowland AA, Voeltz GK. Endoplasmic reticulumendosome contact increases as endosomes traffic and mature. Hegde RS, editor. Mol Biol Cell. 2013;24: 1030-1040. doi:10.1091/mbc.E12-10-0733

68. Rowland AA, Chitwood PJ, Phillips MJ, Voeltz GK. ER contact sites define the position and timing of endosome fission. Cell. 2014;159: 1027-1041. doi:10.1016/j.cell.2014.10.023

69. Korge P, Calmettes G, Weiss JN. Increased reactive oxygen species production during reductive stress: The roles of mitochondrial glutathione and thioredoxin reductases. Biochim Biophys Acta. NIH Public Access; 2015;1847: 514-25. doi:10.1016/j.bbabio.2015.02.012

70. Nordberg J, Zhong L, Holmgren A, Arnér ES. Mammalian thioredoxin reductase is irreversibly inhibited by dinitrohalobenzenes by alkylation of both the redox active selenocysteine and its neighboring cysteine residue. J Biol Chem. American Society for Biochemistry and Molecular Biology; 1998;273: 10835-42. doi:10.1074/JBC.273.18.10835

71. Ochi R, Dhagia V, Lakhkar A, Patel D, Wolin MS, Gupte SA. Rotenone-stimulated superoxide release from mitochondrial complex I acutely augments L-type $\mathrm{Ca}^{2+}$ current in A7r5 aortic smooth muscle cells. Am J Physiol Circ Physiol. 2016;310: H1118-H1128. doi:10.1152/ajpheart.00889.2015

72. Lubos E, Loscalzo J, Handy DE. Glutathione peroxidase-1 in health and disease: From molecular mechanisms to therapeutic opportunities [Internet]. Antioxidants and Redox Signaling. Mary Ann Liebert, Inc.; 2011. pp. 1957-1997. doi:10.1089/ars.2010.3586

73. Brown DI, Griendling KK. Nox proteins in signal transduction [Internet]. Free Radical Biology and Medicine. Free Radic Biol Med; 2009. pp. 1239-1253. doi:10.1016/j.freeradbiomed.2009.07.023

74. Aguet F, Antonescu CN, Mettlen M, Schmid SL, Danuser G. Advances in analysis of low signal-to-noise images link dynamin and AP2 to the functions of an endocytic checkpoint. Dev Cell. 2013;26: 279-291. doi:10.1016/j.devcel.2013.06.019

75. Hofmann I. An N-terminally acetylated Arf-like GTPase is localised to lysosomes and affects their motility. J Cell Sci. 2006;119: 1494-1503. doi:10.1242/jcs.02958 
Figure 1: Different ROS inducers produce different ROS in RAW macrophages. (A) RAW

906

907

908

909

910

911

912

913

914

915

916

917

918 cells were exposed to vehicle, or to one of the following ROS inducers $-1 \mathrm{mM} \mathrm{H}_{2} \mathrm{O}_{2} 40 \mathrm{~min}, 1$ $\mu \mathrm{M}$ rotenone $60 \mathrm{~min}, 10 \mu \mathrm{M}$ CDNB $30 \mathrm{~min}$, or $5 \mu \mathrm{M}$ MCB $30 \mathrm{~min}$. Cells were then stained with CellROX Green to detect and quantify the levels of ROS formed during these treatments.

Fluorescence micrographs represent single z-focal plane images from spinning disc confocal microscopy. Scale bar $=20 \mu \mathrm{m}$. (B) Quantification of CellROX Green fluorescence intensity. C) MCB-GSH adduct was also detected during vehicle or MCB treatment. Fluorescence micrographs represent single $\mathrm{z}$-focal plane images from spinning disc confocal microscopy.

Scale bar $=20 \mu \mathrm{m}$. (D) Quantification of MCB-GSH fluorescence intensity. E-H: Quantification of ROS-specific probes, where HPF detects hydroxyl and perinitrite (E), Si-DMA detects singlet oxygen (F), Mitosox detects mitochondrial superoxide (G), and ROS-ID detects cytoplasmic superoxide (H). For each ROS probe, fluorescence was normalized against the respective vehicle control. For all graphs, data are represented as mean \pm S.E.M. from three independent experiments with 40-50 cells assessed per treatment condition per experiment. One-way ANOVA and Tukey's post-hoc test were used for (B, E-H), and an unpaired Student's t-test performed for $(\mathrm{D}) . *$ indicates $\mathrm{p}<0.05$.

\section{Figure 2. ROS agonists prevent lysosome enlargement during acute PIKfyve suppression. $A$ :}

RAW cells pre-labelled with Lucifer yellow and exposed to vehicle or $20 \mathrm{nM}$ apilimod for $40 \mathrm{~min}$. These conditions were then supplemented with additional vehicle or $1 \mathrm{mM} \mathrm{H}_{2} \mathrm{O}_{2}$ for $40 \mathrm{~min}, 1 \mu \mathrm{M}$ rotenone for $60 \mathrm{~min}, 10 \mu \mathrm{M} \mathrm{CDNB}$ for $30 \mathrm{~min}, 5 \mu \mathrm{M} \mathrm{MCB}$ for $30 \mathrm{~min}$ or auranofin $10 \mu \mathrm{M}$ for $120 \mathrm{~min}$. Fluorescence micrographs are represented as z-projections of 45-55 z-plane images obtained by spinning disc microscopy. Scale bar: $5 \mu \mathrm{m} . B-D$ : Quantification of individual 
929 lysosome volume (B), lysosome number per cell (C), and total lysosome volume per cell (D). Data

930 represent mean \pm S.E.M. from three independent experiments, with 25-30 cells assessed per

931 treatment condition per experiment. One-way ANOVA and Tukey's post-hoc test was used, where

$932 *$ indicates statistical significance between indicated conditions $(p<0.05)$.

934 Figure 3. ROS scavengers permit lysosome coalescence during acute PIKfyve suppression.

935 A: RAW cells pre-labelled with Lucifer yellow and exposed to vehicle, or $0.5 \mu \mathrm{M}$ rotenone 60

$936 \mathrm{~min}$, or $10 \mathrm{mM} \mathrm{N}$-acetyl-L-cysteine (NAC) $120 \mathrm{~min}$ alone, or in presence of $20 \mathrm{nM}$ apilimod for

937 the last $40 \mathrm{~min}$. Fluorescence micrographs are represented as z-projections of 45-55 z-plane images

938 obtained by spinning disc microscopy. Scale bar: $5 \mu \mathrm{m}$. B-D: Quantification of individual

939 lysosome volume (B), lysosome number per cell (C), and total lysosome volume per cell (D). Data

940 represent mean \pm S.E.M. from three independent experiments, with 25-30 cells assessed per

941 treatment condition per experiment. One-way ANOVA and Tukey's post-hoc test was used, where

$942 *$ indicates statistical significance between indicated conditions $(p<0.05)$.

944 Figure 4: ROS accelerate recovery of lysosome size and number upon PIKfyve reactivation.

945 (A) Top two rows: RAW cells pre-labelled with Lucifer yellow were exposed to either vehicle, 1 $946 \mathrm{mM} \mathrm{H}_{2} \mathrm{O}_{2} 40 \mathrm{~min}, 1 \mu \mathrm{M}$ rotenone $60 \mathrm{~min}, 10 \mu \mathrm{M}$ CDNB $30 \mathrm{~min}$, or $5 \mu \mathrm{M} \mathrm{MCB} 30 \mathrm{~min}$. Bottom

947 two rows: alternatively, RAW cells were first treated with $20 \mathrm{nM}$ apilimod for $60 \mathrm{~min}(0 \mathrm{~h})$,

948 followed by apilimod removal and replenishment with complete media for $2 \mathrm{~h}$ in the presence of 949 vehicle, $\mathrm{H}_{2} \mathrm{O}_{2}$, rotenone, $\mathrm{CDNB}$, or $\mathrm{MCB}$ at previously indicated concentrations. Fluorescence 950 micrographs are spinning disc microscopy images with $45-55$ z-planes represented as $\mathrm{z}$ 951 projections. Scale bar: $5 \mu \mathrm{m}$. (B-D) Quantification of individual lysosome volume (B), lysosome 
952 number per cell (C), and total lysosome volume per cell (D). Data are represented as mean \pm s.e. $m$.

953 from three independent experiments, with 25-30 cell assessed per treatment condition per

954 experiment. One-way ANOVA and Tukey's post-hoc test used for B-D, where * indicates

955 statistically significant difference between control conditions $(P<0.05)$.

Figure 5: Apilimod integrity and PtdIns(3,5)P 2 levels are not altered by ROS. (A) RAW cells

959 pre-labelled with Lucifer yellow. Following reactions were performed in complete media in vitro

960 for designated time, prior to adding to cells for an additional 40 min: vehicle; $1 \mathrm{mM} \mathrm{H}_{2} \mathrm{O}_{2} 40 \mathrm{~min}$;

$96120 \mathrm{nM}$ apilimod $40 \mathrm{~min} ; 20 \mathrm{nM}$ apilimod preincubated with $1 \mathrm{mM} \mathrm{H} \mathrm{O}_{2}$ for $40 \mathrm{~min} ; 20 \mathrm{nM}$

962 apilimod preincubated with $0.5 \mathrm{mg} / \mathrm{L}$ catalase for $60 \mathrm{~min} ; 1 \mathrm{mM} \mathrm{H} \mathrm{O}_{2}$ exposed to $0.5 \mathrm{mg} / \mathrm{L}$ catalase

963 for 60 min to neutralize $\mathrm{H}_{2} \mathrm{O}_{2}$, followed by $20 \mathrm{nM}$ apilimod $40 \mathrm{~min}$; or $20 \mathrm{nM}$ apilimod exposed

964 to $1 \mathrm{mM} \mathrm{H}_{2} \mathrm{O}_{2}$ for 40 min to test whether $\mathrm{H}_{2} \mathrm{O}_{2}$ degraded apilimod, followed by $0.5 \mathrm{mg} / \mathrm{L}$ catalase

965 for 60 min to degrade $\mathrm{H}_{2} \mathrm{O}_{2}$. Fluorescence micrographs are spinning disc microscopy images with

966 45-55 z-planes represented as z-projections. Scale bar: $5 \mu \mathrm{m}$. (B-D) Quantification of individual

967 lysosome volume (B), lysosome number per cell (C), and total lysosome volume per cell (D). AP

968 (apilimod), CAT (catalase). Data are shown as mean \pm s.e.m. from three independent experiments,

969 with 25-30 cell assessed per treatment condition per experiment. One-way ANOVA and Tukey’s

970 post-hoc test used for B-D; * indicates statistical difference against control condition $(P<0.05)$. (E-

971 F) ${ }^{3} \mathrm{H}$-myo-inositol incorporation followed by HPLC-coupled flow scintillation used to determine

972 PtdIns(3)P and PtdIns(3,5) $\mathrm{P}_{2}$ levels from RAW cells exposed to vehicle alone, or $1 \mathrm{mM} \mathrm{H}_{2} \mathrm{O}_{2} 40$

$973 \min (\mathrm{E})$, or $1 \mu \mathrm{M}$ rotenone $60 \mathrm{~min}(\mathrm{~F})$, in presence or absence of $20 \mathrm{nM}$ apilimod. Data represent 
$974 \pm$ s.d. from three independent experiments. One-way ANOVA and Tukey's post-hoc test used for

975 E-F; * indicates statistical difference against control condition $(P<0.05)$.

977 Figure 6. ROS agents differentially affect the microtubule system. Representative single z-

978 focal plane immunofluorescence micrographs of RAW cells (A) or RPE cells (E) treated with

979 vehicle, $\mathrm{H}_{2} \mathrm{O}_{2}$, rotenone, $\mathrm{CDNB}$ or $\mathrm{MCB}$ at previously used time periods and at the indicated

980 concentrations. After treatment with ROS agents, cells were fixed and immunostained with anti-

$981 \alpha$-tubulin antibodies. Quantification of number of microtubule junctions per cell, number of

982 microtubule branches per cell and average microtubule branch length respectively for RAW cells

983 (B-D) and RPE cells (F-H), and patch area in RPE cells (I). Data are represented as mean \pm SEM

984 from three independent experiments, with 50-70 cells assessed per treatment per experiment for

985 RAW cells (A-D) and 15-20 cells assessed per treatment per experiment for RPE cells (E-I). One-

986 way ANOVA and Tukey's post-hoc test used for B-D and F-I, where * indicates statistically

987 significant difference between control conditions $(P<0.05)$. Scale bar: $10 \mu \mathrm{m}(\mathrm{A})$ or $20 \mu \mathrm{m}(\mathrm{E})$.

988

989 Figure 7: Distinct ROS agents differentially impact lysosome motility. RAW cells (A-C,

990 Movies 1-6) or RPE cells (D-F, Movies 7-13) were pre-labelled with Lucifer yellow and exposed

991 to either vehicle, $1 \mathrm{mM} \mathrm{H} \mathrm{O}_{2} 40 \mathrm{~min}, 1 \mu \mathrm{M}$ rotenone $60 \mathrm{~min}, 10 \mu \mathrm{M}$ CDNB $30 \mathrm{~min}, 5 \mu \mathrm{M} \mathrm{MCB}$

$99230 \mathrm{~min}$, or $5 \mu \mathrm{M}$ or $10 \mu \mathrm{M}$ nocodazole for $60 \mathrm{~min}$. Live-cell spinning disc confocal microscopy

993 was performed at a single, mid-cell z-focal plane once every 4 sec for 3 min for RAW cells or

994 every $8 \mathrm{sec}$ for $6 \mathrm{~min}$ for RPE cells. Quantification of lysosome speed (A, D), lysosome track

995 length (B, E), and lysosome displacement (C,F) for RAW cells (A-C) or RPE cells (D-F). Data are

996 represented as mean \pm s.d. from three independent experiments. One-way ANOVA and Tukey’s 
997 post-hoc test used for B-D, where * indicates $P<0.05$ between indicated conditions and control.

998 Supplemental Movies 1-13 are representative of the live-cell imaging from which shown data was

999 derived from.

1000

1001 Figure 8: $\mathrm{H}_{2} \mathrm{O}_{2}$ hinders phagosome-lysosome fusion. (A) RAW cells were treated with $\mathrm{H}_{2} \mathrm{O}_{2}$ or

1002 vehicle $\left(\mathrm{H}_{2} \mathrm{O}\right)$ for $1 \mathrm{~h}$ before introducing ZsGreen-expressed E. coli (green). RAW cells were

1003 incubated for 20 minutes in the presence of bacteria and $\mathrm{H}_{2} \mathrm{O}_{2}$ or vehicle, then RAW cells were

1004 washed with PBS, and further incubated in media containing $\mathrm{H}_{2} \mathrm{O}_{2}$ or vehicle for an additional 40

1005 minutes. External bacteria were labeled with rabbit anti-E. coli antibodies (blue) and were

1006 excluded from analysis using a mask. LAMP-1 was labeled with rat anti-LAMP-1 antibodies (red).

1007 (B) Quantification of mean LAMP-1 intensity on bacteria-containing phagosomes. LAMP-1

1008 intensities were quantified from regions that co-localized to internal bacteria (green signal and no

1009 blue signal). Data represented as a scatter plot, where each dot is an individual phagosome from $\mathrm{n}$

$1010=144$ to 179 cells across all independent experiments and conditions. Mean \pm standard deviation

1011 from three independent experiments is indicated as well. Data analyzed with two-tailed unpaired

1012 t-test $(*$ indicates $\mathrm{p}<0.05)$.

1013

1014 Figure 9: $\mathbf{H}_{2} \mathbf{O}_{2}$ and rotenone do not induce lysosome damage as detected by galectin-3 puncta.

1015 (A). Macrophages expressing galectin-3-GFP were labelled with Alexa546-conjugated dextran 1016 and then exposed to vehicle, rotenone, or $\mathrm{H}_{2} \mathrm{O}_{2}$ for $\sim 1 \mathrm{~h}$, or with LLOMe for $2 \mathrm{~h}$ as a positive 1017 control. Live-cell imaging was done by spinning disc confocal. Scale bar $=10 \mu \mathrm{m}$. (B) Mean 1018 number of galectin-3-GFP puncta per cell based on 25-30 cells per condition per experiment from 
$1019 \mathrm{n}=3$ independent experiments. One-way ANOVA and Tukey's post-hoc test was used, where *

1020 indicates $P<0.05$ in relation to vehicle condition and ns indicates not significant.

1022 Figure 10: ROS regulate lysosome coalescence independently of $\mathbf{C a}^{2+}$. (A) RAW cells were 1023 pre-labelled with Alexa546-conjugated dextran, followed by labelling with the $\mathrm{Ca}^{2+}$ sensor, Fluo41024 AM. Cells were treated with vehicle, or $1 \mathrm{mM} \mathrm{H}_{2} \mathrm{O}_{2}$ for $40 \mathrm{~min}$, or $1 \mu \mathrm{M}$ rotenone for $60 \mathrm{~min}$. 1025 Fluorescence micrographs represent single z-plane images obtained by spinning disc microscopy. 1026 Scale bar: $5 \mu \mathrm{m}$. (B) Ratio of Fluo4-AM fluorescence intensities associated with Alexa ${ }^{546}$ 1027 conjugated dextran and cytosol. Data are represented as mean \pm SEM from three independent 1028 experiments, with 20-25 cells assessed per treatment per experiment. Two-way ANOVA and 1029 Tukey's post-hoc test were used for (B), where * indicates $P<0.05$ against control conditions. (C) 1030 RAW cells were pre-labelled with Lucifer yellow and exposed to either vehicle, $1 \mathrm{mM} \mathrm{H}_{2} \mathrm{O}_{2}$ for $103140 \mathrm{~min}, 1 \mu \mathrm{M}$ rotenone for $60 \mathrm{~min}$, or $50 \mu \mathrm{M}$ BAPTA-AM for $70 \mathrm{~min}$, with or without $20 \mathrm{nM}$ 1032 apilimod. Additionally, cells were co-treated with BAPTA-AM and $\mathrm{H}_{2} \mathrm{O}_{2}$ or BAPTA-AM and 1033 rotenone, before adding apilimod. Fluorescence micrographs are spinning disc microscopy images 1034 with 45-55 z-planes represented as z-projections. Scale bar: $5 \mu \mathrm{m}$. (D-F) Quantification of 1035 individual lysosome volume (D), lysosome number per cell (E), and total lysosome volume per 1036 cell $(\mathrm{F})$. Data is illustrated as mean \pm SEM from three independent experiments, with 25-30 cell 1037 assessed per condition per experiment. One-way ANOVA and Tukey's post-hoc test used for B1038 D with $* P<0.05$ compared to indicated control conditions. 
1042 vehicle alone, $1 \mathrm{mM} \mathrm{H} \mathrm{H}_{2} \mathrm{O}_{2}$ for $40 \mathrm{~min}, 1 \mu \mathrm{M}$ ikarugamcyin for $1 \mathrm{~h}$, or $20 \mathrm{nM}$ apilimod for $60 \mathrm{~min}$.

1043 For a subgroup of cells treated with apilimod, drug was replaced with fresh media containing either

1044 vehicle, $1 \mathrm{mM} \mathrm{H} \mathrm{O}_{2}, 1 \mu \mathrm{M}$ ikarugamcyin, or $1 \mathrm{mM} \mathrm{H}_{2} \mathrm{O}_{2}$ and $1 \mu \mathrm{M}$ ikarugamycin for $2 \mathrm{~h}$.

1045 Fluorescence micrographs are spinning disc microscopy images with 45-55 z-planes represented

1046 as z-projections. Scale bar: $5 \mu \mathrm{m}$. (B-D) Quantification of individual lysosome volume (B),

1047 lysosome number per cell (C), and total lysosome volume per cell (D). Data are shown as mean \pm 1048 s.e.m. from three independent experiments, with 25-30 cell assessed per treatment condition per 1049 experiment. One-way ANOVA and Tukey's post-hoc test used for B-D, where * indicates $P<0.05$ 1050 between experimental and control conditions.

1052 Figure 12: ROS promote actin clearance from lysosomes and actin depolymerization abates 1053 lysosomes coalescence during PIKfyve inhibition. (A) RAW cells pre-labelled with Alexa ${ }^{488}$ 1054 conjugated dextran followed by treatment with vehicle, $20 \mathrm{nM}$ apilimod for 40 min alone, or in 1055 presence of $10 \mu \mathrm{M}$ CDNB for $30 \mathrm{~min}$ or $1 \mu \mathrm{M}$ rotenone for $60 \mathrm{~min}$. Cells were fixed with $4 \%$ PFA 1056 and stained for actin with phalloidin. Fluorescence micrographs were captured by spinning disc 1057 confocal as single z-planes. The inset is a magnified portion of field of view tracking Alexa ${ }^{488}$ 1058 conjugated dextran lysosome(s), phalloidin-stained actin, and as merged channels. Scale bar: 2 $1059 \mu \mathrm{m}$. (B) Cells were assessed for number of actin puncta structures associated with lysosomes. Data 1060 represent mean \pm S.E.M. from three independent experiments, with $60-80$ cells assessed per 1061 treatment condition across three experiments. One-way ANOVA and Tukey's post-hoc test was 1062 used, where * indicates statistical significance between indicated conditions $(p<0.05)$. (C) RAW 1063 cells were pre-labelled with Lucifer yellow and exposed to vehicle or $20 \mathrm{nM}$ apilimod for $1 \mathrm{~h}$, 1064 followed by apilimod removal at 0 or $2 \mathrm{~h}$. These conditions were then supplemented with 
1065 additional vehicle or $1 \mu \mathrm{M}$ latrunculin $\mathrm{A}$ or $5 \mu \mathrm{M}$ cytochalasin B for $1 \mathrm{~h}$. Fluorescence micrographs 1066 are represented as z-projections of 45-55 z-plane images obtained by spinning disc confocal

1067 microscopy. Scale bar: $5 \mu \mathrm{m}$. D-F: Quantification of individual lysosome volume (D), lysosome 1068 number per cell (E), and total lysosome volume per cell (F). Data represent mean \pm S.E.M. from

1069 three independent experiments, with 25-30 cells assessed per treatment condition per experiment. 1070 One-way ANOVA and Tukey's post-hoc test was used, where * indicates statistical significance 1071 between indicated conditions $(p<0.05)$.

1072

1073 Supplemental Materials

1074 Supplemental Figure S1: Lower $\mathbf{H}_{2} \mathbf{O}_{2}$ concentration prevents apilimod induced lysosome

1075 coalescence. (A) RAW cells were pre-labelled with Lucifer yellow and exposed to either vehicle, $1076100 \mu \mathrm{M} \mathrm{H}_{2} \mathrm{O}_{2}$ for $40 \mathrm{~min}$ in presence or absence of $1 \mathrm{nM}$ or $5 \mathrm{nM}$ apilimod $40 \mathrm{~min}$. Scale bar: 5 $1077 \mu \mathrm{m}$. (B-D) Quantification of individual lysosome volume (B), lysosome number per cell (C), and 1078 total lysosome volume per cell (D). Data are illustrated as mean \pm SEM from three independent 1079 experiments, with 25-30 cell assessed per condition per experiment. One-way ANOVA and 1080 Tukey's post-hoc test was used, where * indicates $P<0.05$ for the indicated conditions.

1082 Supplemental Figure S2: ROS prevent lysosome enlargement during acute PIKfyve 1083 suppression in HeLa and RPE cells. (A) HeLa cells pre-labelled with Lucifer yellow and exposed 1084 to vehicle or $100 \mathrm{nM}$ apilimod $40 \mathrm{~min}$, or with $1 \mathrm{mM} \mathrm{H}_{2} \mathrm{O}_{2}$ in the presence or absence of $100 \mathrm{nM}$ 1085 apilimod for $40 \mathrm{~min}$. Scale bar: $10 \mu \mathrm{m}$. (B-D) Quantification of individual lysosome volume per 1086 lysosome (B), lysosome number per cell (C), and total lysosome volume per cell (D). (E) RPE 1087 cells pre-labelled with Lucifer yellow and exposed to vehicle, or $1 \mathrm{mM} \mathrm{H} \mathrm{H}_{2}$, or $10 \mu \mathrm{M} \mathrm{CDNB}$, 
1088 in presence or absence of $200 \mathrm{nM}$ apilimod $40 \mathrm{~min}$. Scale bar: $20 \mu \mathrm{m}$. (F-H) Quantification of 1089 individual lysosome volume $(\mathrm{F})$, lysosome number per cell $(\mathrm{G})$, and sum lysosome volume per

1090 cell $(\mathrm{H})$. For $(\mathrm{B}-\mathrm{D})$ and $(\mathrm{F}-\mathrm{H})$, data are represented as mean \pm SEM. from three independent

1091 experiments, with 25-30 cells assessed for (B-D) and 15-20 cells assessed for (F-H) per treatment

1092 condition per experiment. One-way ANOVA and Tukey's post-hoc test used with $* P<0.05$

1093 compared to indicated control conditions.

1094

1095 Supplemental Figure S3: Quantification and validation of microtubule morphology by image

1096 analysis. Single z-focal plane immunofluorescence micrographs of RAW cells (A) or RPE cells

1097 (E) treated with vehicle, $\mathrm{H}_{2} \mathrm{O}_{2}$ or rotenone. After treatment with ROS agents, cells were fixed and

1098 immunostained with anti- $\alpha$-tubulin antibodies. Cells were analyzed for their microtubule

1099 morphology using the ImageJ "skeleton" plugin, converting images into binary "skeleton"

1100 micrographs. Quantification of number of microtubule junctions per cell, number of microtubule

1101 branches per cell and average microtubule branch length for RAW cells (B-D) and RPE cells (F-

$1102 \mathrm{H})$. RPE cells were also analyzed for maximum microtubule patch area per cell (I) through ImageJ

1103 using binary filter and watershed segmentation. Data are represented as mean \pm SD from 5

1104 different fields of view for RAW cells or 10 different fields of view for RPE cell, with 50-70 cells

1105 assessed per treatment condition for RAW cells (A-D) and 15-20 cells assessed per treatment

1106 condition for RPE cells (E-H). One-way ANOVA and Tukey's post-hoc test used for B-D and F-

$1107 \mathrm{H}$, where * indicates statistically significant difference between control conditions $(P<0.05)$. Scale

1108 bar: $20 \mu \mathrm{m}(\mathrm{A}, \mathrm{E})$. 


\section{Supplemental Figure S4: Increased microtubule stability does not affect lysosome motility}

1111 or lysosome coalescence during PIKfyve inhibition. (A) RAW cells pre-labelled with Lucifer

1112 yellow were exposed to either vehicle, or $1 \mu \mathrm{M}$ or $10 \mu \mathrm{M}$ paclitaxel for 60 min in presence or

1113 absence of $20 \mathrm{nM}$ apilimod for the remaining $40 \mathrm{~min}$. Scale bar: $5 \mu \mathrm{m}$. (B-D) Quantification of

1114 individual lysosome volume (B), lysosome number per cell (C), and total lysosome volume per

1115 cell (D). Data are represented as mean \pm s.e.m. from three independent experiments, with 25-30

1116 cell assessed for (B-D) per treatment condition per experiment. (E-G) RAW cells pre-labelled with

1117 Lucifer yellow were exposed to vehicle or $1 \mu \mathrm{M}$ or $10 \mu \mathrm{M}$ paclitaxel $60 \mathrm{~min}$. Live cell spinning

1118 disc confocal microscopy was performed at single z-focal plane once every 4 sec for 3 min.

1119 Quantification of lysosome speed (E), lysosome displacement (F), and lysosome track length (G)

1120 are shown. Data are represented as mean \pm s.d. from three independent experiments. One-way

1121 ANOVA and Tukey's post-hoc tests were used, where * indicates $P<0.05$ between experimental

1122 and control conditions. Data is based on movies like those represented by Movies 14-16.

\section{Supplemental Figure S5. ROS do not affect Rab7 activation and Arl8b loading onto}

1125 lysosomes. RAW cells expressing RILPC33-GFP (A), or Arl8bWT-GFP (B), exposed to vehicle

1126 in absence or presence of $20 \mathrm{nM}$ apilimod $40 \mathrm{~min}$, or $1 \mathrm{mM} \mathrm{H}_{2} \mathrm{O}_{2} 40 \mathrm{~min}$ in presence or absence

1127 of $20 \mathrm{nM}$ apilimod $40 \mathrm{~min}$. Scale bar: $5 \mu \mathrm{m}$. (C-D) Quantification of membrane associated

1128 fluorescence intensity of RILPC33-GFP (C) from (A) or Arl8bWT-GFP (D) from (B), normalized

1129 to cytosol fluorescence intensity. Data represent mean \pm SEM from three independent experiments,

1130 with 15-20 cell assessed per treatment condition per experiment. One-way ANOVA and Tukey's

1131 post-hoc test used for C-D with $* P<0.05$ compared to indicated control conditions. (E) A

1132 representative Western blot of membrane fractions from RAW macrophages treated with vehicle, 
1133 rotenone, or $\mathrm{H}_{2} \mathrm{O}_{2}$ with or without apilimod. Blots were probed with antibodies against Rab7,

$1134 \mathrm{Arl}$ (8a/b, and LAMP1, the latter used to benchmark membrane levels. (F) Relative levels of

1135 Arl8ab/b or Rab7 as a ratio to LAMP1 band intensity. Data are shown as mean + standard deviation

1136 from $\mathrm{n}=3$ independent experiments.

1138 Supplemental Figure $\mathbf{S 6}$. $\mathrm{H}_{2} \mathrm{O}_{2}$ boosts recruitment of clathrin and dynamin to membranes.

1139 (A) RPE cells stably expressing clathrin heavy chain-eGFP were pre-labelled with Alexa ${ }^{546-}$

1140 conjugated dextran and treated with vehicle, $1 \mathrm{mM} \mathrm{H}_{2} \mathrm{O}_{2}$, or $200 \mathrm{nM}$ apilimod with or without 1

$1141 \mathrm{mM} \mathrm{H} \mathrm{H}_{2}$. Single $\mathrm{z}$ - plane images were acquired every $2 \mathrm{~min}$ for $40 \mathrm{~min}$ across all treatments.

1142 Fluorescence micrographs represent single z-plane images at 0 min and $40 \mathrm{~min}$ for each treatment

1143 obtained by spinning disc microscopy. The inset is a magnified portion of field of view tracking

1144 Alexa ${ }^{546}$-conjugated dextran lysosome(s) or clathrin-eGFP separate or merged. Scale bar: $7 \mu \mathrm{m}$.

1145 B. Ratio of clathrin-eGFP fluorescence intensities associated with Alexa ${ }^{546}$-conjugated dextran

1146 and cytosol time points: 0, 10, 20, 30, and $40 \mathrm{~min}$. Data are represented as mean \pm s.e.m. from five

1147 to six independent experiments, with 1-3 cells assessed per treatment condition per experiment.

1148 Two-way ANOVA and Tukey's post-hoc test were used for (B), where * indicates $P<0.05$ against

1149 control conditions. (C) RAW cells were treated with vehicle or $1 \mathrm{mM} \mathrm{H}_{2} \mathrm{O}_{2}$ for 40 min, lysed and

1150 homogenates fractionated through a sucrose gradient ultracentrifugation. Fractions were

1151 immunoblotted against LAMP1 and VAPB to respectively identify lysosome and ER fractions,

1152 and aganst clathrin heavy chain and dynamin 2. Protein expression for clathrin heavy chain (D) or

1153 dynamin 2 (E) were normalized to LAMP1 for fractions 3 to 6 . Data are represented as mean \pm

1154 s.d. from three independent experiments. Unpaired Student's t-test was used for (D-E), where *

1155 indicates $P<0.05$ against vehicle control conditions. 
1157 Supplemental Figure S7. Dynamin inhibition does not affect lysosome fragmentation during

1158 during PIKfyve reactivation. (A) RAW cells were pre-labelled with Lucifer yellow and exposed

1159 to either vehicle, $30 \mu \mathrm{M}$ dyngo-4A for $2 \mathrm{~h}, 1 \mathrm{mM} \mathrm{H}_{2} \mathrm{O}_{2}$ for $40 \mathrm{~min}$, or $1 \mu \mathrm{M}$ rotenone for $1 \mathrm{~h}$, or

$116020 \mathrm{nM}$ apilimod for $60 \mathrm{~min}$. Additional subgroup of apilimod treated cells were then washed and

1161 incubated with apilimod-free media and changed for $2 \mathrm{~h}$ in the presence of vehicle, dyngo-4A,

$1162 \mathrm{H} 2 \mathrm{O} 2$, and dyngo4-A plus $\mathrm{H} 2 \mathrm{O} 2$ for a total time of $2 \mathrm{~h}$ without apilimod. Fluorescence

1163 micrographs are spinning disc microscopy images with $45-55$ z-planes represented as z-

1164 projections. Scale bar: $5 \mu \mathrm{m}$. (B-D) Quantification of individual lysosome volume (B), lysosome

1165 number per cell (C), and total lysosome volume per cell (D). Data is illustrated as mean \pm s.e.m.

1166 from three independent experiments, with 25-30 cell assessed per treatment condition per

1167 experiment. One-way ANOVA and Tukey's post-hoc test used for B-D with $* P<0.05$ compared

1168 to indicated control conditions.

1175 Supplemental Movie 1: Lysosome motility for vehicle-treated RAW macrophages. Live-cell

1176 imaging of RAW macrophages pre-labelled with Lucifer yellow and treated with vehicle-only.

1177 Single-plane acquired every $4 \mathrm{sec}$ for $3 \mathrm{~min}$. Time and scale are as indicated. 
1179 Supplemental Movie 2: Lysosome motility for $\mathbf{H}_{2} \mathbf{O}_{2}$-treated $\mathbf{R A W}$ macrophages. Live-cell

1180 imaging of RAW macrophages pre-labelled with Lucifer yellow and treated with $1 \mathrm{mM} \mathrm{H}_{2} \mathrm{O}_{2}$ for

$118140 \mathrm{~min}$. Single-plane acquired every $4 \mathrm{sec}$ for $3 \mathrm{~min}$. Time and scale are as indicated.

1183 Supplemental Movie 3: Lysosome motility for rotenone-treated RAW macrophages. Live-

1184 cell imaging of RAW macrophages pre-labelled with Lucifer yellow and treated with $1 \mu \mathrm{M}$

1185 rotenone for $60 \mathrm{~min}$. Single-plane acquired every $4 \mathrm{sec}$ for $3 \mathrm{~min}$. Time and scale are as indicated.

Supplemental Movie 4: Lysosome motility for CDNB-treated RAW macrophages. Live-cell

1188 imaging of RAW macrophages pre-labelled with Lucifer yellow and treated with $10 \mu \mathrm{M}$ CDNB

$118930 \mathrm{~min}$. Single-plane acquired every $4 \mathrm{sec}$ for $3 \mathrm{~min}$. Time and scale are as indicated.

1191 Supplemental Movie 5: Lysosome motility for MCB-treated RAW macrophages. Live-cell

1192 imaging of RAW macrophages pre-labelled with Lucifer yellow and treated with $5 \mu$ M MCB 30

1193 min. Single-plane acquired every $4 \mathrm{sec}$ for $3 \mathrm{~min}$. Time and scale are as indicated.

1195 Supplemental Movie 6: Lysosome motility for nocodazole-treated RAW macrophages. Live-

1196 cell imaging of RAW macrophages pre-labelled with Lucifer yellow and treated with $10 \mu \mathrm{M}$

1197 nocodazole $60 \mathrm{~min}$. Single-plane acquired every $4 \mathrm{sec}$ for $3 \mathrm{~min}$. Time and scale are as indicated.

1199 Supplemental Movie 7: Lysosome motility for vehicle-treated RPE cells. Live-cell imaging of

1200 RPE cells pre-labelled with Lucifer yellow and treated with vehicle-only. Single-plane acquired 1201 every $8 \mathrm{sec}$ for $6 \mathrm{~min}$. Time and scale are as indicated. 
1203 Supplemental Movie 8: Lysosome motility for $\mathbf{H}_{2} \mathbf{O}_{2}$-treated RPE cells. Live-cell imaging of

1204 RPE cells pre-labelled with Lucifer yellow and treated with $1 \mathrm{mM} \mathrm{H}_{2} \mathrm{O}_{2} 40$ min. Single-plane

1205 acquired every $8 \mathrm{sec}$ for $6 \mathrm{~min}$. Time and scale are as indicated.

1207 Supplemental Movie 9: Lysosome motility for rotenone-treated RPE cells. Live-cell imaging 1208 of RPE cells pre-labelled with Lucifer yellow and treated with $1 \mu \mathrm{M}$ rotenone 60 min. Single1209 plane acquired every $8 \mathrm{sec}$ for $6 \mathrm{~min}$. Time and scale are as indicated.

1211 Supplemental Movie 10: Lysosome motility for CDNB-treated RPE cells. Live-cell imaging 1212 of RPE cells pre-labelled with Lucifer yellow and treated with $10 \mu \mathrm{M}$ CDNB $30 \mathrm{~min}$. Single-plane 1213 acquired every $8 \mathrm{sec}$ for $6 \mathrm{~min}$. Time and scale are as indicated.

1215 Supplemental Movie 11: Lysosome motility for MCB-treated RPE cells. Live-cell imaging of

1216 RPE cells pre-labelled with Lucifer yellow and treated with $5 \mu$ M MCB 30 min. Single-plane 1217 acquired every $8 \mathrm{sec}$ for $6 \mathrm{~min}$. Time and scale are as indicated.

1219 Supplemental Movie 12: Lysosome motility for nocodazole five micromolar treated RPE

1220 cells. Live-cell imaging of RPE cells pre-labelled with Lucifer yellow and treated with $5 \mu \mathrm{M}$ 1221 nocodazole $60 \mathrm{~min}$. Single-plane acquired every $8 \mathrm{sec}$ for $6 \mathrm{~min}$. Time and scale are as indicated. 
1223 Supplemental Movie 13: Lysosome motility for nocodazole ten micromolar treated RPE

1224 cells. Live-cell imaging of RPE cells pre-labelled with Lucifer yellow and treated with $10 \mu \mathrm{M}$

1225 nocodazole $60 \mathrm{~min}$. Single-plane acquired every $8 \mathrm{sec}$ for $6 \mathrm{~min}$. Time and scale are as indicated.

1226

1227 Supplemental Movie 14: Lysosome motility for vehicle-treated RAW macrophages. Live-cell

1228 imaging of RAW cells pre-labelled with Lucifer yellow and treated with vehicle-only. Single-

1229 plane acquired every $4 \mathrm{sec}$ for $3 \mathrm{~min}$. Time and scale are as indicated.

1231 Supplemental Movie 15: Lysosome motility for paclitaxel one micromolar treated RAW

1232 macrophages. Live-cell imaging of RAW cells pre-labelled with Lucifer yellow and treated with

$12331 \mathrm{MM}$ paclitaxel $60 \mathrm{~min}$. Single-plane acquired every $4 \mathrm{sec}$ for $3 \mathrm{~min}$. Time and scale are as

1234 indicated.

1235

1236 Supplemental Movie 16: Lysosome motility for paclitaxel ten micromolar treated RAW

1237 macrophages. Live-cell imaging of RAW cells pre-labelled with Lucifer yellow and treated with

$123810 \mu \mathrm{M}$ paclitaxel $60 \mathrm{~min}$. Single-plane acquired every $4 \mathrm{sec}$ for $3 \mathrm{~min}$. Time and scale are as

1239 indicated.

1240

1241 


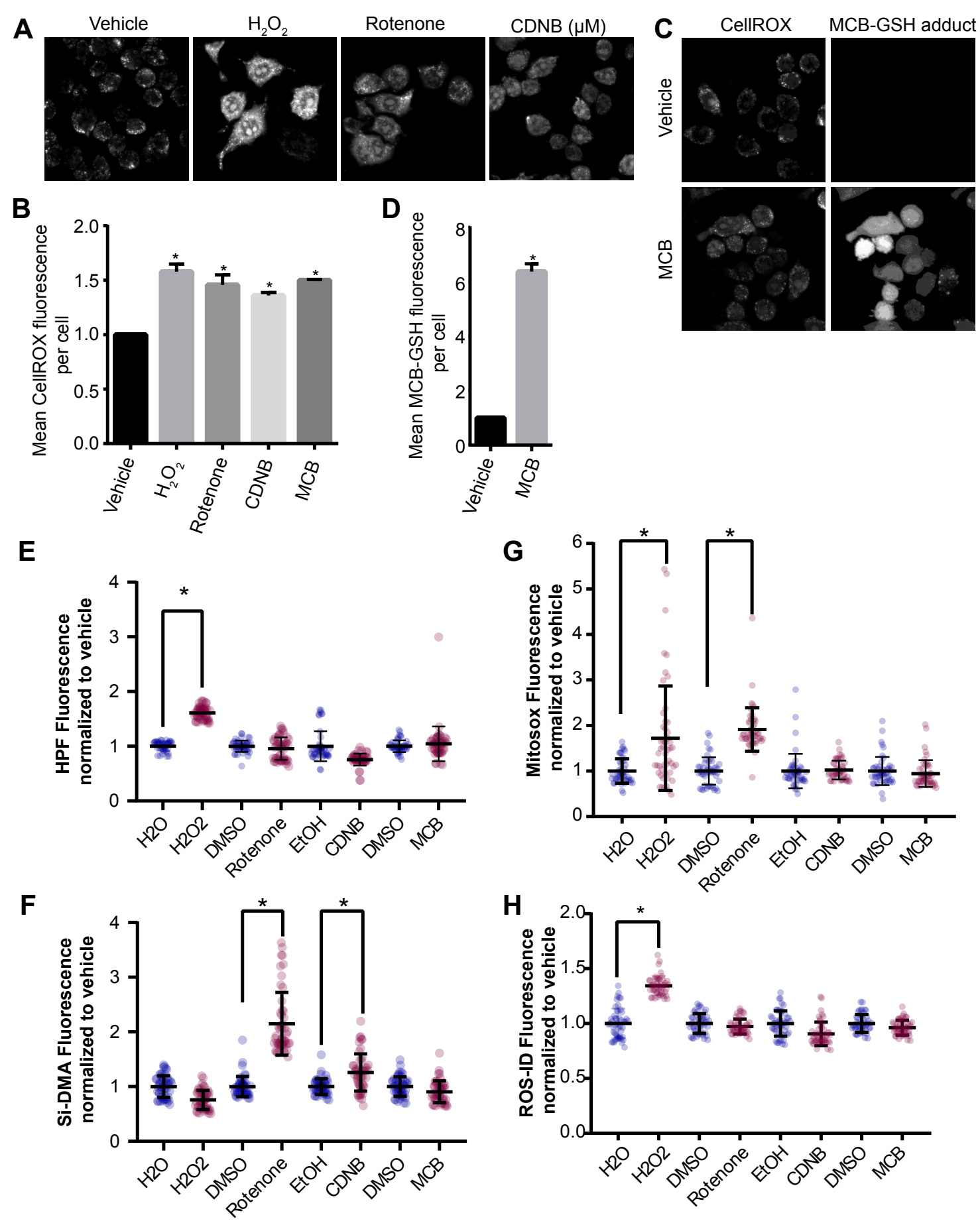

Figure 1 
$A$
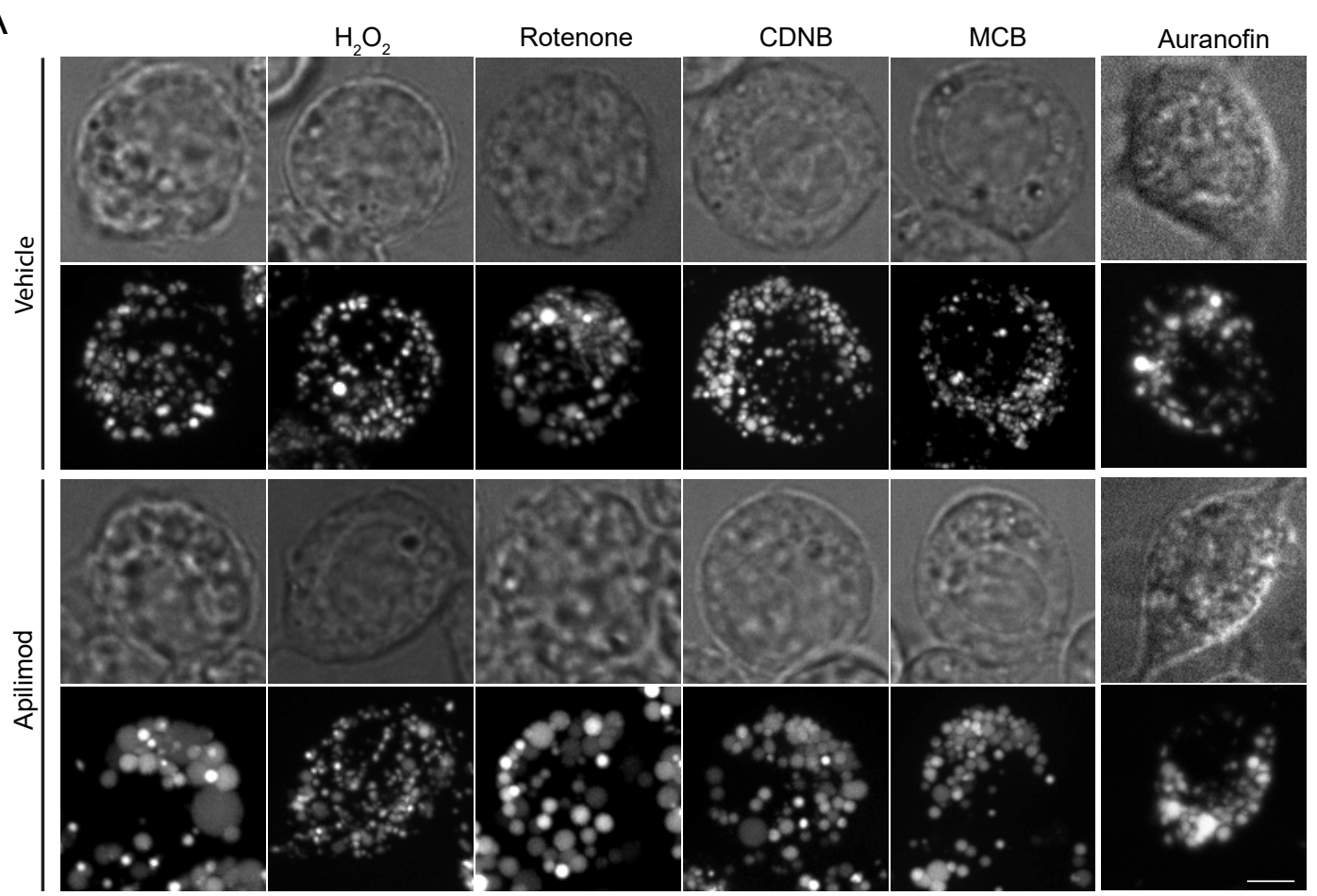

B

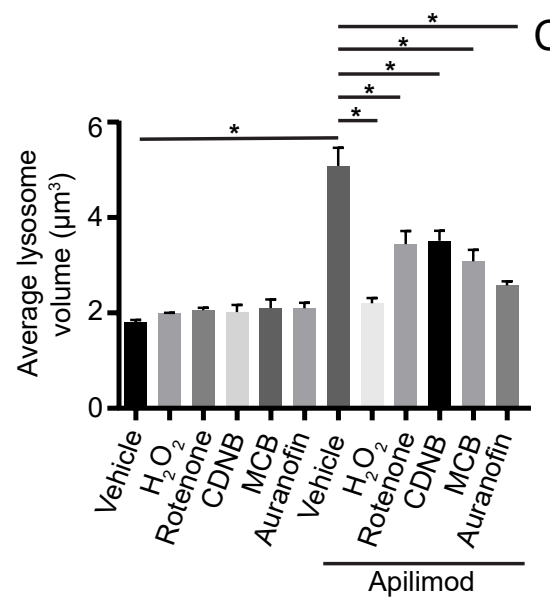

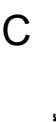

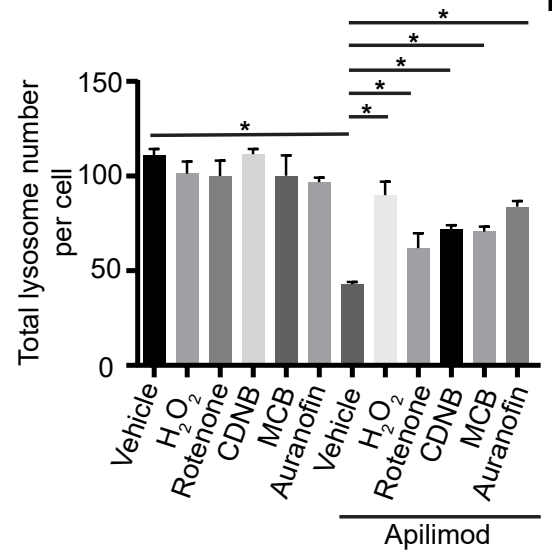

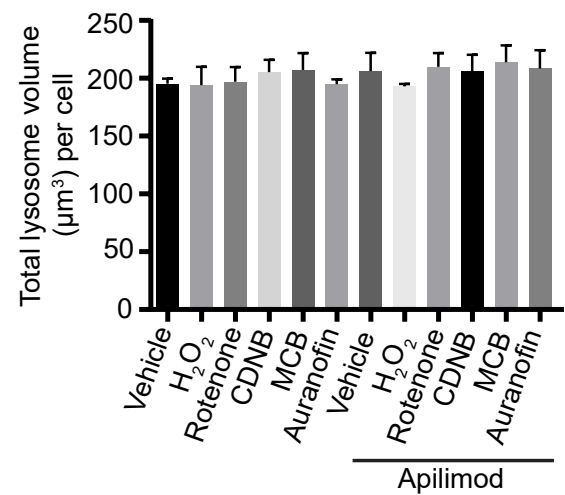

Figure 2 

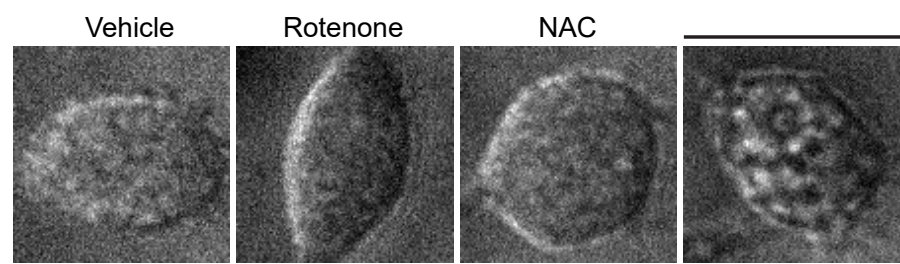

Apilimod
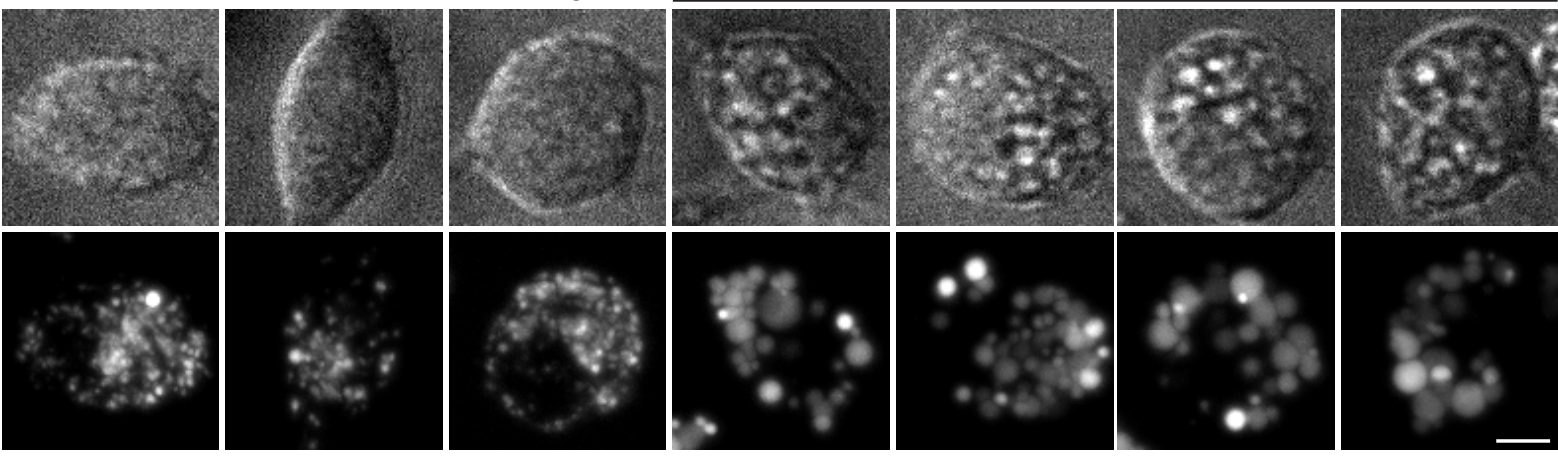

B

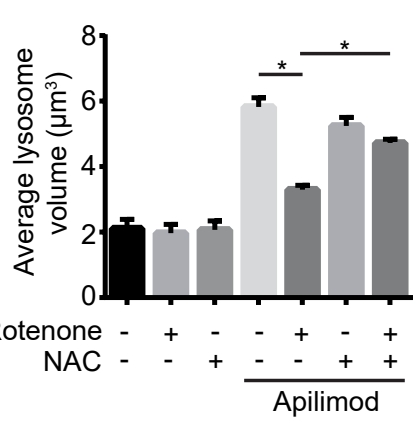

C

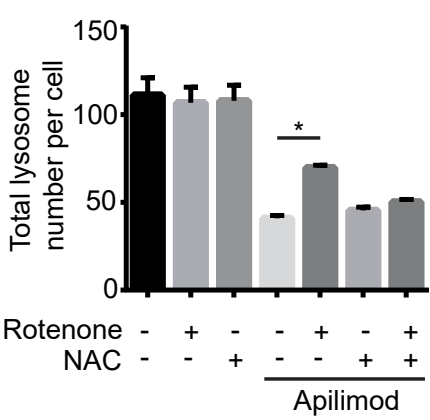

D

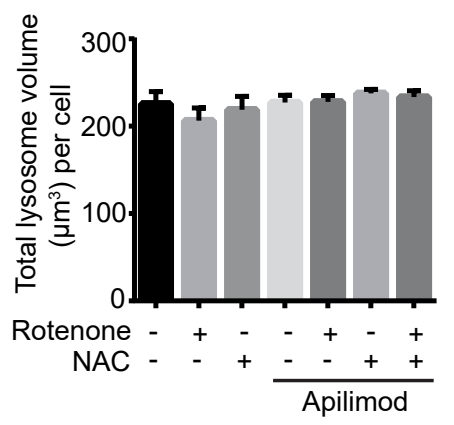

Figure 3 

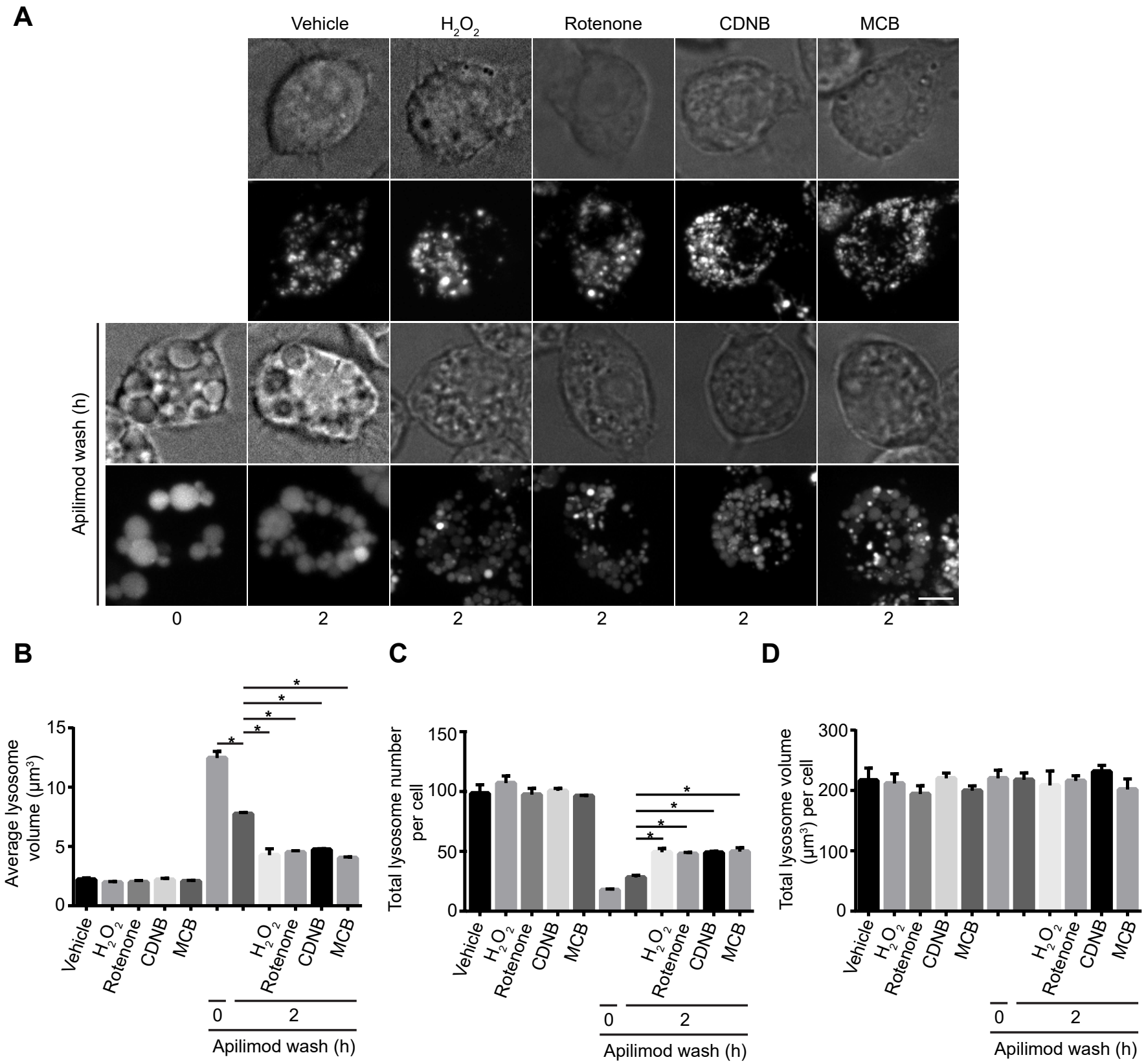

Figure 4 
A
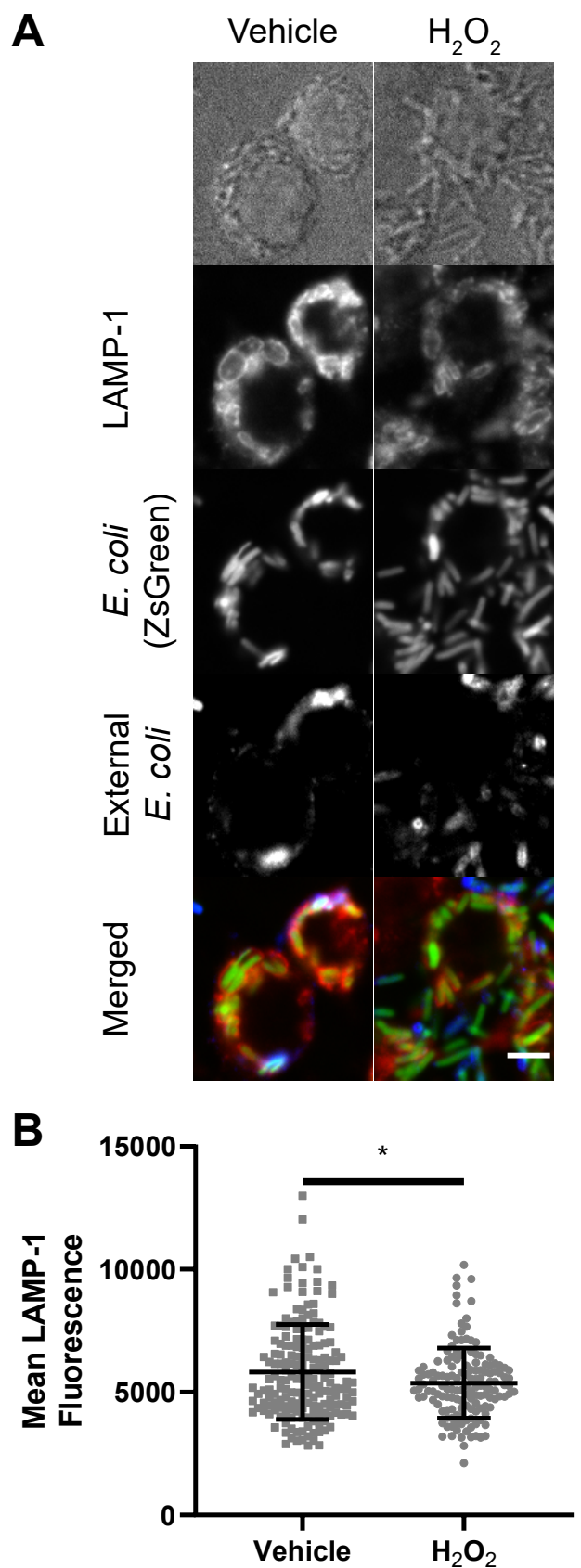

Figure 8 
A
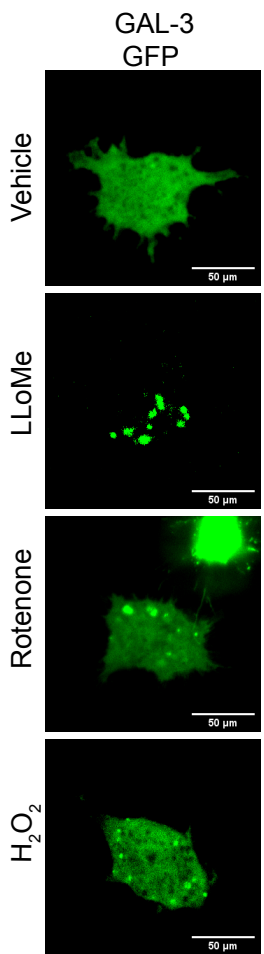

Alexa546-

dextran
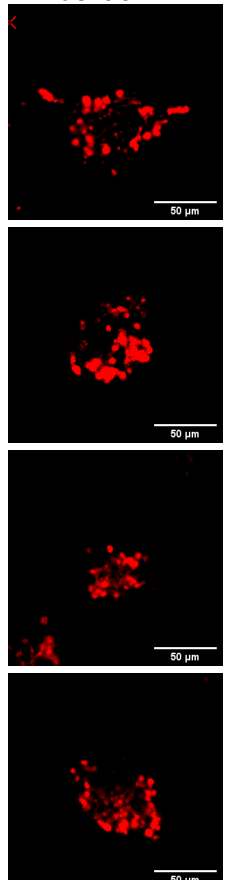

Merged
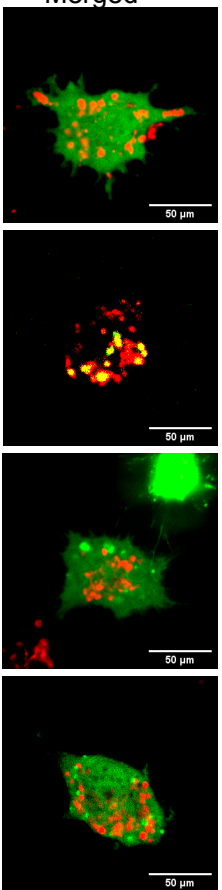

B

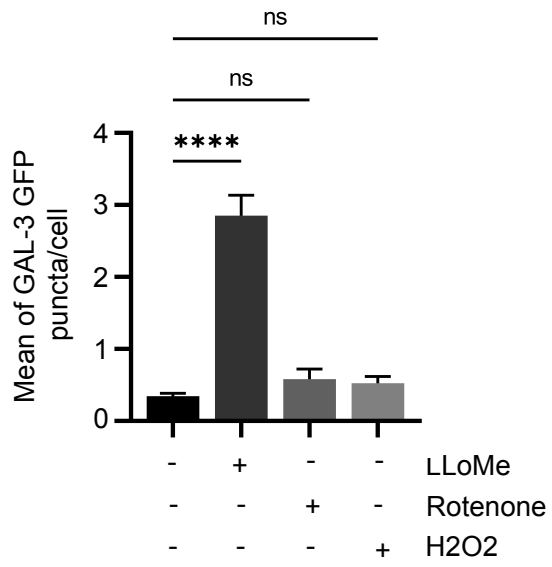

Figure 9 


\section{$\mathbf{A}$}

V

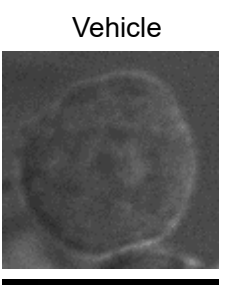

Rotenone

$\mathrm{H}_{2} \mathrm{O}_{2}$
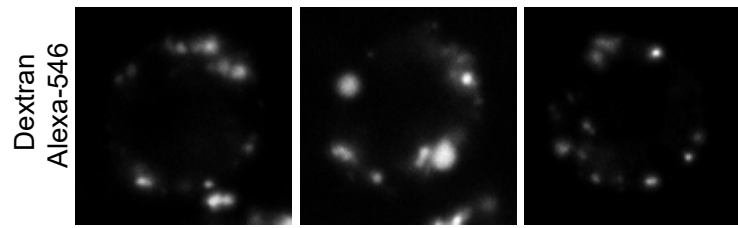

过
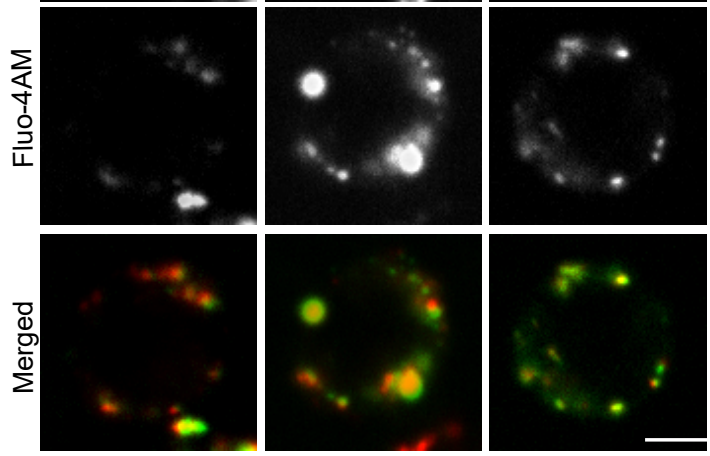

B

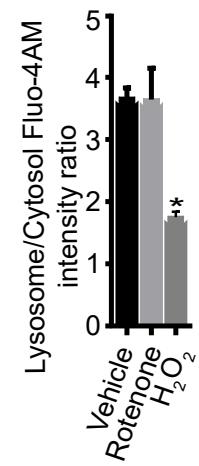

D

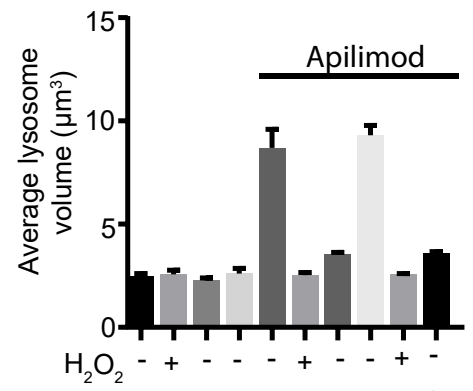

Rotenone - - + - - + - +
Rotenone

BAPTA
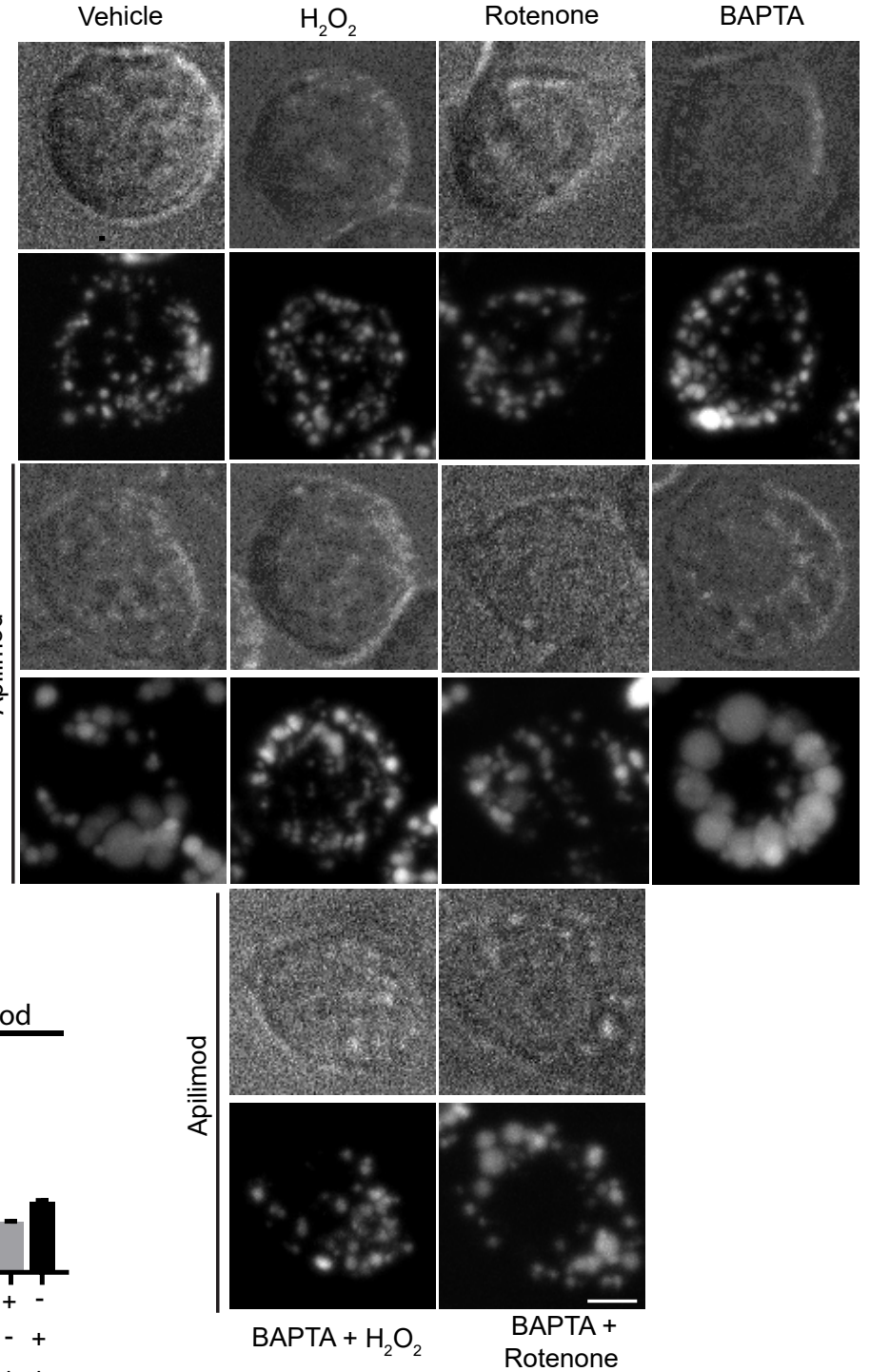

Rotenone
E

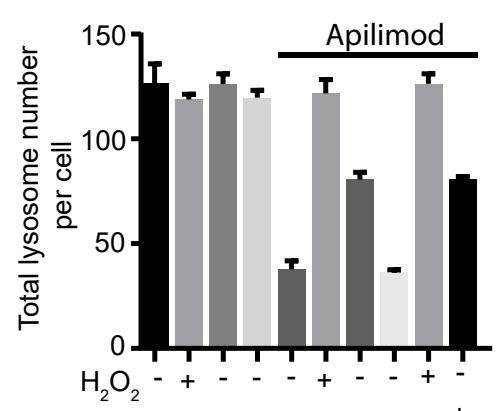

Rotenone - - + - - + - +

BAPTA - - $+-\cdots++$
F

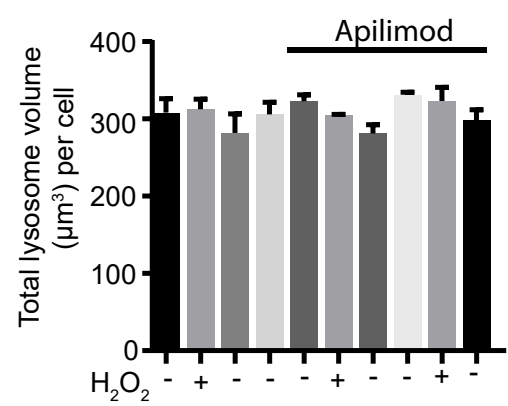

Rotenone - - + - - + - +

BAPTA - - + - - + +
Figure 10 
